R I C H A R D G ILBER T

University of California at Berkeley

C A R L S H A P I R O

University of California at Berkeley

\title{
Antitrust Issues in the Licensing of Intellectual Property: The Nine No-No's Meet the Nineties
}

"KNOWLEDGE ASSETS" - research and development know-how and intellectual property protected by patent, copyright, and trade secrethave become increasingly important as a determinant of U.S. industrial progress.' In 1995 seven knowledge-intensive industries (aerospace, computers, communications equipment, electrical machinery, electronic components, instruments, and drugs) accounted for 27 percent of total manufacturing output in the United States, up from 21 percent in 1982. ${ }^{2}$ Royalties and fees collected by U.S. firms from international trade in intellectual properties exceeded $\$ 20$ billion in 1993, nearly double the amount collected just five years earlier. ${ }^{3}$ Licensing royalties and fees, although considerable, greatly understate the value of intellectual property to the U.S. economy. Technology licensing and related

Both authors are professors at the University of California at Berkeley and have served recently as Deputy Assistant Attorney General for Economics in the Antitrust Division, U.S. Department of Justice. Gilbert led a task force that drafted the Antitrust Guidelines for the Licensing of Intellectual Property, which were issued by the Department of Justice and the Federal Trade Commission in April 1995. The views expressed here, both generally and with respect to specific matters reviewed by the Antitrust Division, are those of the authors alone, and do not reflect official positions of the Justice Department. The authors give special thanks to Robert Gertner, Louis Kaplow, and Ilya Segal for valuable comments on an earlier draft.

1. For convenience, in what follows we will often use the term "patent" to denote intellectual property more generally, including copyright and trade secrets. Of course, there are important differences in the statutory protection that is afforded to each regime.

2. U.S. Bureau of the Census (1996, table 1).

3. National Science Board (1996, table 6-2). 
partnerships are essential in today's economy to remain globally competitive and to market the products that knowledge assets help to create. $^{4}$

This paper examines the historical role of antitrust enforcement for licensing and other arrangements involving the transfer of intellectual property rights. We briefly review past statements by the U.S. Department of Justice on licensing and discuss the new antitrust guidelines for licensing intellectual property (IP) that the Justice Department and Federal Trade Commission published in 1995. We focus on competitive issues raised by exclusivity provisions in IP licensing and discuss several recent cases that address exclusive licenses and other competition issues related to the use of intellectual property.

\section{The IP-Antitrust Conflict and the Nine No-No's}

A reasoned analysis of antitrust and intellectual property respects both the role of the IP laws in creating and protecting property rights to encourage investment in research and development and the role of the antitrust laws in protecting consumers from anticompetitive restraints of trade. Until recently, the U.S. courts and antitrust authorities shunned a direct evaluation of this trade-off and focused instead on whether the practice in question extends a patentee's economic power beyond the legitimate scope of the patent grant. ${ }^{5}$ In the $1970 \mathrm{~s}$ the Antitrust Division of the Department of Justice announced a "watch list" of nine specified licensing practices that the division viewed as anticompetitive restraints of trade in licensing agreements. The list soon came to be known as the "Nine No-No's.", They consisted of the following:

4. This very point was stressed recently in a Federal Trade Commission report entitled "Competition Policy in the New High-Tech, Global Marketplace.' See FTC (1996).

5. Newburg and Tom (1997).

6. The list of nine potentially offending technology licensing practices was first outlined by Bruce Wilson in "Patent and Know-How License Arrangements: Field of Use, Territorial, Price and Quantity Restrictions,' a speech delivered on November 6, 1970 , in Boston. Wilson gave two other speeches that recited the list of proscribed licensing practices. See "Is The Past Prologue, or Where Do We Go From Here?," delivered on September 21, 1972, in Detroit and reprinted in 5 Trade Reg. Rep. 50, 
1. Royalties not reasonably related to sales of the patented products;

2. Restraints on licensees' commerce outside the scope of the patent (tie-outs);

3. Requiring the licensee to purchase unpatented materials from the licensor (tie-ins);

4. Mandatory package licensing;

5. Requiring the licensee to assign to the patentee patents that may be issued to the licensee after the licensing arrangement is executed (exclusive grantbacks);

6. Licensee veto power over grants of further licenses;

7. Restraints on sales of unpatented products made with a patented process;

8. Post-sale restraints on resale; and

9. Setting minimum prices on resale of the patent products.

Briefly, most of the Nine No-No's involve attempts by patent holders to extend their patent monopolies to unpatented supplies, to gain control over improvements of their innovations, to determine prices for resale of their patented products, or to engage in market allocations.

We find it useful to divide up the no-no's into several groups. The first three practices directly impose restraints on the licensee's ability to use products outside the scope of the patent, or impose "penalties" for such use. The fourth practice, package licensing, can have this impact as well in some limited circumstances where it acts like a tie. Our analysis of "penalty clauses" below is meant to inform antitrust policy regarding these four practices. The fifth practice, grantbacks, often serves pro-competitive purposes but can in theory stifle innovation, especially if the grantbacks are exclusive. The sixth practice is akin to granting the licensee an exclusive license. ${ }^{7}$ The last three practices fit more in the area of vertical control (such as resale price maintenance) and receive little attention in this discussion.

The extent to which the Nine No-No's reflected actual Department

146.; and "Law on Licensing Practices: Myth or Reality? or Straight Talk from 'Alice in Wonderland,',' delivered on January 21, 1975, to the American Patent Lawyers Association in Washington, D.C.

7. The 1995 guidelines distinguish between exclusive licenses, which merely restrict the right of the licensor to license others, and exclusive dealing, which may restrict the licensee from selling or using competing technologies. See DOJ and FTC (1995, p. 20). 
of Justice antitrust policy is uncertain. Their author, Deputy Assistant Attorney General Bruce Wilson, declared that they are restraints " . . . which in virtually all cases are going to lead to antitrust trouble because of their adverse effect upon competition." ${ }^{8}$ In actuality, of the sixteen cases filed by the division's Intellectual Property Section between the late 1960s and the late 1970s, only half specifically addressed any of the nine practices. Moreover, almost all of these cases were litigated under a rule of reason rather than per se illegality.

\section{The IP Guidelines}

In the early 1980s the Antitrust Division began to question the theory underlying the Nine No-No's, focusing on the principle that unconstrained patent licensing increases the value of patents and encourages licensing and innovation. In 1988 the division formalized its view of the rights of patent holders in its "Antitrust Enforcement Guidelines for International Operations." The 1988 policy adopted a "rule-ofreason" approach to patent licensing that allowed for a balancing of the pro-competitive effects of licensing against possible anticompetitive effects in related markets.

A fundamental principle of the 1988 guidelines was that the owner of intellectual property rights is entitled to maximize the market value of its intellectual property - that is, the rights holder is entitled to the area under the derived demand curve for its intellectual property. Under this view only licensing practices that leverage the demand for its property (shift demand to the right) potentially run afoul of the antitrust laws. ${ }^{9}$ The 1988 guidelines did not explain, however, how a holder of IP rights could "leverage" demand for its intellectual property or under what circumstances such conduct would harm consumers or competition.

8. From his speech of January 21,1975 (p. 9); see footnote 6. It is not clear whether Wilson considered the restraints on this list to be per se violations of the antitrust laws, although he noted that ". . . the validity of licensing practices other than these nine is to be tested under the rule of reason." (p. 10).

9. Charles F. Rule, "The Antitrust Implications of International Licensing: After the Nine No-No's," a speech before the Legal Conference, Cincinnati, Ohio, October 21,1986, p. 10. 
The Department of Justice and the Federal Trade Commission (FTC) released new "Antitrust Guidelines for the Licensing of Intellectual Property', (IP guidelines) on April 6, 1995. The new guidelines share the core principles expressed in the section on technology licensing in the 1988 guidelines. These include

- An explicit recognition of the generally pro-competitive nature of licensing arrangements;

- A clear rejection of any presumption that intellectual property necessarily creates market power in the antitrust context; and

- An endorsement of the validity of applying the same general antitrust approach to the analysis of conduct involving intellectual property that the agencies apply to conduct involving other forms of tangible or intangible property.

These three core principles provide a foundation for the policy statements in the 1995 guidelines. Because licensing often has significant efficiency benefits (for example, by facilitating the integration of the licensed property with complementary factors of production), antitrust concerns that may arise in licensing arrangements normally will be evaluated under the rule of reason. The absence of a presumption that intellectual property necessarily creates market power implies that an antitrust evaluation of licensing restraints such as tying arrangements normally will require investigation of market circumstances to establish anticompetitive effects. Although the special privileges and characteristics of intellectual property could conceivably form the basis for a sui generis competition policy, there is no theory that would clearly justify different rules. Instead, the basic principle espoused in the 1995 IP guidelines is that the antitrust laws are sufficiently flexible to take important differences into account and should not impose greater or lesser scrutiny for intellectual property than for other forms of property.

The new guidelines advance the principle that a licensing arrangement may raise antitrust concerns if it harms competition that would have occurred in the absence of the license. Licenses that have such an effect do not necessarily lower overall economic welfare. The harm to competition should be compared to other pro-competitive effects of the arrangements. In applying this principle, it is useful to distinguish licenses between actual or potential competitors, that is, "horizontal 
licenses," and all others, which can be called "vertical licenses.",10 Both horizontal and vertical licenses can harm competition that would have occurred in the absence of the license.

Licensing arrangements between actual and potential competitors are relatively easy to assess under the principle of "harm to competition that would have occurred in the absence of the license.' For example, consider a situation in which two parties each possess patent rights that can be used to make substitute products. Suppose each accuses the other of infringing its patent, and they agree to a settlement to resolve their disputes. Suppose further that the settlement consists of a crosslicensing agreement that allocates exclusive territories to each of the firms. Clearly, this licensing agreement can eliminate competition between the parties that would have occurred in the absence of the license. The strength of the infringement claims is critical to assessing such a settlement and the resulting cross-license. If the claims were weak, the settlement is likely to be anticompetitive. If the claims were strongfor example, if each firm held a patent blocking the other-then there could be no competition, indeed no sales at all, in the absence of the cross-license, so the settlement cannot harm competition.

Most licensing arrangements are vertical, however; they do not involve licenses between actual or potential competitors. Nonetheless, these arrangements may affect competition that would have occurred in the absence of the license. An example is a licensing arrangement between a licensor and a licensee that forecloses competition from new entrants. Much of this paper focuses on vertical licenses.

In the spirit of the guidelines, we develop in the next section a model of penalty clauses in vertical licensing contracts. By "penalty clause" we mean a provision in a license that imposes costs on the licensee if the licensee uses alternative suppliers or technologies. We distinguish between licensing terms that are favorable to the licensee, and thus encourage the licensee to employ the licensed technology, and penalty clauses, which also encourage the licensee to employ the licensed technology, but by penalizing the alternatives. By imposing a cost on the licensee if the licensee does business with another firm, a penalty clause may harm competition by reducing the demand available to rival firms,

10. Of course, in a trivial sense, all licenses are vertical, inasmuch as one firm is selling technology to another, so the two are in a supplier-buyer relationship. 
by increasing rival firms' costs of doing business, or by softening competition among rivals. The extreme case of a penalty clause is exclusive dealing, in which the licensee signs a license prohibiting the licensee from using any substitute technologies. Note that several of the Nine No-No's involve some form of penalty clause.

A central question is not whether a specific provision in a licensing contract can harm competition, but whether buyers and sellers would voluntarily enter into contracts containing provisions that have such effects. In developing the theoretical model below, we discuss various circumstances in which contracts between buyers and sellers may harm competition, yet be mutually advantageous to the parties to the contract.

\section{A Model of Penalty Clauses}

Obviously, the possible permutations, or even all the interesting ones, that describe possible market environments, cannot be addressed in a single model. We have chosen to focus on an environment with a single incumbent licensor (seller) with a first-mover advantage, a single licensee (buyer), and a potential entrant. Thus, we do not formally address coordination among licensees in dealing with the licensor, and we quite consciously assume that would-be innovators are not at the bargaining table when initial licenses are signed. Because innovation confers natural first-mover advantages, it is reasonable to assume that potential entrants are absent from the initial bargaining between the licensor and the licensee.

We also assume that all three parties can engage in efficient ex post negotiations and renegotiations: once investments have been made, inventions achieved, and uncertainty resolved, the parties can bargain efficiently and write sophisticated contracts. This assumption reflects our view that many important licensing contracts take place between sophisticated parties for whom the transactions costs of negotiating are small relative to the magnitude of the payoffs involved (although we recognize that bargaining can in reality be highly inefficient whether the stakes are large or small). Finally, we assume that the parties make noncontractible investments.

The framework for our model is very close to that of Segal and 
Whinston, on whom we rely heavily. ${ }^{11}$ In many respects the analysis in Segal and Whinston is more general than ours, and we are happy to acknowledge that several of the effects we highlight in this section are identified in their paper as well. Our main departure from Segal and Whinston is that we study explicit contracts between the buyer and seller, while they compare an exclusive dealing contract with no contract. They assume that the buyer and seller "cannot specify a positive quantity, because the nature of the trade is hard to describe in advance." ${ }^{2}$ Our analysis applies to circumstances in which the buyer and seller can specify terms on which they will trade with each other, as well as penalties the buyer must pay to the seller if the buyer deals with the entrant. Permitting a specific contract between the buyer and seller alters the ex post bargaining game, because under our assumptions the buyer has the right to purchase from the seller without the need to enter into ex post negotiations with the seller. We are also able to study the effects of varying the strength of the penalty clause.

\section{Players, Contracts, and Timing}

Our analysis involves three parties: a licensor or technology seller, $S$, a licensee or technology buyer, $B$, and a (potential) entrant, $E$. We are interested in circumstances in which the licensor, by virtue of early innovation, has a natural first-mover advantage in signing a contract with the buyer. We believe this structure is especially fitting for the licensing of intellectual property: the first firm to obtain a patent has a first-mover advantage, and, furthermore, future innovators often are not present at the bargaining table prior to their own inventions and thus their own entry.

We look at three distinct phases or periods. In the first phase the buyer and the seller negotiate a contract that gives the buyer the right to make purchases from the seller in the future according to specified terms. ${ }^{13}$ More specifically, defining the buyer's ultimate unit purchases

11. Segal and Whinston (1997). Our model is also similar in many respects to that in Spier and Whinston (1995).

12. Segal and Whinston (1997, p. 4).

13. It is important to keep in mind that this contract ultimately will not govern the dealings between $B$ and $S$, because they can renegotiate it in the final phase. The contract serves to define the threat points in subsequent bargaining among $B, S$, and $E$. 
from the seller by $x$ and the buyer's unit purchases from the entrant by $y$, the contract gives the buyer the power to pick $x$ and calls for payments from $B$ to $S$ given by $f(x, y, K)$, where the parameters $K$ reflect the terms of the contract.

We are especially interested in provisions that require the buyer to make payments to the seller contingent on the buyer's dealings with the entrant, that is, the way in which $y$ enters into $f$. We define a penalty clause as a term $K$ in the contract that calls for payments only if $y>0$, with these payments independent of $x$ but rising with $y$, for at least some values of $y$. In the differentiable case, this means that $\partial^{2} f(x, y, K) /$ $\partial y \partial K$ is nonnegative for all $(x, y, K)$ and is strictly positive for least some $(x, y, K)$, and that $\partial^{2} f(x, y, K) / \partial x \partial K=0$. An exclusive dealing contract specifies a payment schedule $f(x)$ and requires the buyer to purchase exclusively from the seller. This is equivalent to an infinite penalty payment if $y>0$. A simple contract with per-unit penalties involves a payment schedule $f(x)+K+k y$. This includes the important case in which the buyer agrees to pay the seller for every unit the buyer acquires, whatever the source of that input: $F+p x+K+k y$, where $p$ may equal $k \cdot{ }^{14}$

Because the contract $f$ between $B$ and $S$ is the key object of our analysis, we pause here to explain the restrictions we have imposed on contracting between the buyer and the seller. Essentially, we assume that the only contractible variables are the buyer's ultimate purchases, $x$ and $y$. In particular, we assume that the parties' investments, the seller's and entrant's realized costs, and the buyer's realized value or demand are not contractible. We also confine ourselves to the institution that gives the buyer the choice ex post of what to do: the buyer can demand delivery of any quantity $x$ (including none) and then must make the specified payments to the seller based on his choice. ${ }^{15} \mathrm{We}$ also

14. Other forms of exclusivity incentives arise in practice. An example is rewarding buyers for obtaining a large share of their total purchases from the seller. Airlines have used contracts of this form to induce travel agents to book a large share of customers' flights on their airline. This does not formally fit our definition of a penalty clause because the reward depends on $x$ as well as $y$.

15. This is equivalent to imposing a very large penalty on the seller for failing to deliver what the buyer requests. We do not believe our assumption that the buyer chooses output ex post is critical to our analysis, but we have not yet explored this formally. 
assume that the contract $f$ between the buyer and the seller can be credibly revealed to the entrant by the buyer and seller.

In the second phase, the parties make investments, after which uncertainty is resolved. We study investment decisions by all three parties. The investment levels are denoted by $I_{B}, I_{S}$, and $I_{E}$ respectively; I denotes the vector of investments. In the third stage, following these investments, the realization of uncertainty is captured by the random variable $\theta$; the distribution from which $\theta$ is drawn is common knowledge. The "physical" state of the world ex post is given by $z=(\mathbf{I}, \theta)$. The complete ex post state of the world is described by $z$ and the prevailing contract terms, $K$.

Given the investments and the realization of uncertainty, the ex post benefits and costs are described by three functions: $v(x, y, z)$, which measures the buyer's gross benefits from consuming quantities $(x, y)$; $c_{S}(x, z)$, which measures the seller's cost of producing $x$ units; and $c_{E}(y, z)$, which measures the entrant's cost of producing $y$ units. ${ }^{16}$ These are all true economic costs and thus do not include the sunk investments made by each party. We assume that the parties negotiate efficiently and select $(x, y)$ ex post to maximize their combined payoffs.

\section{Outcomes and Payoffs}

The ultimate outcome or allocation is characterized by the investment levels $\mathbf{I}$, the realization of uncertainty $\theta$, the output levels $(x, y)$, and the payments made among the parties. Denote the (net) payments from player $i$ to player $j$ by $T_{i j}$, for each of the three pairs $B S, B E$, and $S E$. With this notation, the final payoffs of the three firms are given by

$$
\begin{aligned}
& U_{B}=v(x, y, z)-T_{B S}-T_{B E}-\mathrm{I}_{B}, \\
& U_{S}=T_{B S}-T_{S E}-c_{S}(x, z)-I_{S}, \text { and } \\
& U_{E}=T_{S E}+T_{B E}-c_{E}(y, z)-I_{E} .
\end{aligned}
$$

Total welfare is the sum of all three firms' payoffs, or

Giving the seller the right to choose whether to deliver or not is akin to imposing a large fine on the buyer for not dealing with the seller, a contract term that we explicitly study.

16. We are assuming that the production levels equal the usage levels, so the same $x$ and $y$ appear in the benefit and cost functions. Production other than to order could be modeled as an investment. 


$$
W=v(x, y, z)-c_{S}(x, z)-c_{E}(y, z)-I_{B}-I_{S}-I_{E} .
$$

In general, all of the firms' payoffs depend upon $\theta$; we assume the firms are risk neutral, so they are interested ultimately in their expected payoffs, taken over possible realizations of $\theta$. We denote this by $E_{\theta}[\cdot]$ or by using bars to denote expected values.

\section{Contract Bias: General Analysis}

We are interested in how the incentives of the buyer and seller, together, to craft contract terms differ from overall incentives. Because the only other party is the entrant, we are essentially asking how the terms of the contract affect the entrant. One can think of the entrant in our model as a proxy for other buyers whom we do not explicitly model.

Given the contract chosen by $B$ and $S$, as characterized by $K$, the players will make certain investments, $I_{j}^{*}(K)$, leading ultimately to certain expected payoffs, $\bar{U}_{j}(K)$. In setting a generic contract term $K, B$ and $S$ will maximize $\bar{U}_{B}(K)+\bar{U}_{S}(K)$. Thus, at any interior optimum for $K, K^{*}$, we must have

$$
\left.\frac{d \bar{W}}{d K}\right|_{K} * \frac{d \bar{U}_{E}}{d K}
$$

This equation reminds us that to determine whether the buyer and seller have an incentive to elevate a given contractual parameter over the socially optimal levels, we need only look at the impact of that parameter on the entrant's (expected) payoff, $\bar{U}_{E}$. Looking more closely at this term, we have

$$
\frac{d \bar{U}_{E}}{d K}=\frac{\partial \bar{U}_{E}}{\partial K}+\frac{\partial \bar{U}_{E}}{\partial I_{E}} \frac{d I_{E}}{d K}+\frac{\partial \bar{U}_{E}}{\partial I_{B}} \frac{d I_{B}}{d K}+\frac{\partial \bar{U}_{E}}{\partial I_{S}} \frac{d I_{S}}{d K} .
$$

Because $E$ chooses $I_{E}$ optimally, the second term on the right-hand side is zero. Thus, we have

$$
\left.\frac{d \bar{W}}{d K}\right|_{K} *=\frac{\partial \bar{U}_{E}}{\partial K}+\frac{\partial \bar{U}_{E}}{\partial I_{B}} \frac{d I_{B}}{d K}+\frac{\partial \bar{U}_{E}}{\partial I_{S}} \frac{d I_{S}}{d K} .
$$

In words, equation 1 says that the external effect of contractual provisions chosen by $B$ and $S$ can be broken into three parts, each of which 
must be evaluated on an ex ante basis. First is a direct effect: the clause may have some ex post effect on the entrant's payoff. Under the assumption of efficient ex post bargaining, this is purely a rent transfer term, because $K$ has no direct ex post effect on welfare. Anticipation of this rent transfer affects incentives, however, and thus gives rise to the second and third effects, which, although indirect, are not mere transfers. The second route for the contractual clause to affect the entrant's payoff is through the buyer's investment. The third route is analogous, through the seller's investments.

We now must look more closely at the ex post negotiations to explore how contractual provisions affect each of the parties' payoffs and thus their investments and overall efficiency.

\section{Ex Post Negotiations}

We assume for the analysis in this section that the parties engage in efficient ex post negotiations. The assumption of ex post efficient bargaining obviously precludes traditional deadweight loss issues, conditional on the investments made and uncertainty realized. This assumption is in sharp contrast to Aghion and Bolton, who assume that a lowcost entrant will not supply the buyer if a penalty clause in the contract between buyer and seller eliminates the bilateral gains to trade for the buyer-entrant pair. ${ }^{17}$

The assumption of ex post efficiency is consistent with looking at sophisticated parties for whom transaction costs are relatively unimportant. Furthermore, it does not negate all efficiency effects. Rather, it focuses attention on the way in which the parties split any ex post gains from trade, and this in turn has implications for investments that the parties make. In the context of licensing of intellectual property, this focus strikes us as especially appropriate: arguably, long-run welfare hinges more on the incentives to innovate, rather than on pricing issues per se, especially because sophisticated buyers and sellers are able to structure contracts to reduce or eliminate ex post deadweight losses associated with prices in excess of marginal costs.

We recognize that bargaining payoffs are generally sensitive to the bargaining game one assumes. We seek results that are robust with respect to different bargaining institutions and thus make relatively mild

17. Aghion and Bolton (1987). 
axiomatic assumptions about the bargaining institutions. ${ }^{18}$ Under these assumptions each player's bargaining payoff depends linearly on the incremental value that player brings to other coalitions that might form; Shapley value is a special case of this "linear bargaining." We shall assume such "linear bargaining" in what follows.

GENERAL EXPRESSION FOR BARGAINING PAYOFFS. The building blocks for this cooperative bargaining approach are the returns that various coalitions could earn on their own. We denote by $V_{J}$ the total payoff that can be independently achieved by coalition $J$, given the state of nature $(\mathbf{I}, \theta, K)$, which includes the prevailing contractual terms, $K .{ }^{19}$

Under linear bargaining, the payoffs to the players can be written as:

$$
\begin{aligned}
U_{B}= & V_{B}+\alpha_{B}^{S E}\left(V_{B S E}-V_{S E}-V_{B}\right)+\alpha_{B}^{S}\left(V_{B S}-V_{S}-V_{B}\right) \\
& +\alpha_{B}^{E}\left(V_{B E}-V_{E}-V_{B}\right)-I_{B}, \\
U_{S}= & V_{S}+\alpha_{S}^{B E}\left(V_{B S E}-V_{B E}-V_{S}\right)+\alpha_{S}^{B}\left(V_{B S}-V_{B}-V_{S}\right) \\
& +\alpha_{S}^{E}\left(V_{S E}-V_{E}-V_{S}\right)-I_{S}, \text { and } \\
U_{E}= & V_{E}+\alpha_{E}^{B S}\left(V_{B S E}-V_{B S}-V_{E}\right)+\alpha_{E}^{B}\left(V_{B E}-V_{B}-V_{E}\right) \\
& +\alpha_{E}^{S}\left(V_{S E}-V_{S}-V_{E}\right)-I_{E} .
\end{aligned}
$$

We also have restrictions on the nine $\alpha$ parameters:

$$
\begin{aligned}
& \alpha_{B}^{S E}+\alpha_{S}^{B E}+\alpha_{E}^{B S}=1 ; \alpha_{B}^{S}+\alpha_{S}^{B}=\alpha_{E}^{B S} ; \\
& \alpha_{B}^{E}+\alpha_{E}^{B}=\alpha_{S}^{B E} ; \text { and } \alpha_{S}^{E}+\alpha_{E}^{S}=\alpha_{B}^{S E} .
\end{aligned}
$$

These restrictions arise from various adding-up constraints. For example, if $V_{B S E}$ rises by one unit, so must the sum of $U_{B}, U_{S}$, and $U_{E}$, due to ex post efficiency. ${ }^{20}$

18. These assumptions follow Segal and Whinston (1997), who describe them nicely and who cite Weber (1988).

19. We adopt the notational convention of omitting the investment cost terms from the $V_{J}$ values, because the investment costs are sunk by the time the ex post bargaining occurs.

20. There are nine parameters and four equations, leaving five degrees of freedom to characterize the bargaining strengths of each party. These parameters are: each party vs. the other two as a combined entity (two parameters in total, as these three measures must sum to unity); and each party vs. the other one in a one-on-one negotiation (three 
COALITIONAL VALUES. The coalition of the whole achieves

$$
V_{B S E}=\max _{x, y}\left[v(x, y, z)-c_{S}(x, z)-c_{E}(y, z)\right] .
$$

Call these optimal output levels $x^{* *}(z)$ and $y^{* *}(z)$. The buyer-seller coalition can achieve

$$
V_{B S}=\max _{x}\left[v(x, 0, z)-c_{S}(x, z)\right] .
$$

Call this output level $x^{*}(z)$. Observe that neither of these coalition values depends upon the contractual terms, $K$. Note that the entrant's ex post social contribution is equal to the value that $E$ brings to the $B S$ coalition, namely,

$$
\Delta=V_{B S E}-V_{B S},
$$

which also is independent of $K$.

The buyer on his own achieves

$$
V_{B}=\max _{x}[v(x, 0, z)-f(x, 0, K)] .
$$

This is the buyer's maximum value from trading solely with the seller under the original contract terms. Call this output level $x^{\mathrm{B}}(z)$, which is independent of $K$ under our assumption that $f_{K x}=0$.

The buyer-entrant coalition achieves

$$
V_{B E}=\max _{x, y}\left[v(x, y, z)-f(x, y, K)-c_{E}(y, z)\right] .
$$

Call these output levels $\hat{x}(z, K)$ and $\hat{y}(z, K) .{ }^{21}$ The entrant on his own can earn nothing. Thus, the gains from trade between the buyer and the entrant, if any, are given by

$$
\begin{aligned}
G_{B E} \equiv\left[v(\hat{x}, \hat{y}, z)-f(\hat{x}, \hat{y}, K)-c_{E}(\hat{y}, z)\right] & \\
& -\left[v\left(x^{\mathrm{B}}, 0, z\right)-f\left(x^{\mathrm{B}}, 0, K\right)\right] .
\end{aligned}
$$

bilateral pairs to consider). Thus, in the end, we are interested in these five parameters: $\alpha_{E}^{B S} ; \alpha_{S}^{B E} ;$ and $\alpha_{B}^{S}, \alpha_{B}^{E}$, and $\alpha_{E}^{S}$. One easy way to derive and understand all of the restrictions on the parameters is to recognize that the sum of all players' payoffs is invariant with respect to all coalition values, $V_{J}$, except for the coalition of the whole, $V_{B S E}$, which increases the sum of all values one for one. Using this fact with the linear expressions for each player's value gives all the restrictions on the $\alpha$ s. In the special case of Shapley value, we have $\alpha_{E}^{B S}=\alpha_{S}^{B E}=\alpha_{B}^{S E}=1 / 3$, and $\alpha_{j}^{k}=1 / 6$ for $j \neq k$.

21. If the buyer and entrant have no gains from trade, then we have $\hat{x}(z, K)=x^{B}(z)$. 
Using the envelope theorem and the fact that $\partial f\left(x^{\mathrm{B}}, 0, K\right) / \partial K=0$, we have

$$
\frac{\partial G_{B E}}{\partial K}=-\frac{\partial f(\hat{x}, \hat{y}, K)}{\partial K}
$$

This expression is negative for a penalty clause; stiffer penalties reduce the gains from trade between the buyer and the entrant. Differentiating with respect to $I_{j}$, and using $f_{K x}=0$, we also have

$$
\frac{\partial^{2} G_{B E}}{\partial K \partial I_{j}}=-f_{K y} \frac{\partial \hat{y}}{\partial I_{j}},
$$

for any firm $j$. This is useful later.

Next consider how well $S$ does on her own. This is a bit tricky, because the seller's payoff depends upon the buyer's choice of $(x, y)$, which in turn depends upon whether $B$ is dealing with $E$. We assume here that if $S$ is on her own, $B$ and $E$ make their optimal choices together. Thus, we have

$$
V_{S}=f[\hat{x}(z, K), \hat{y}(z, K), K]-c_{S}[\hat{x}(z, K), z] .
$$

The buyer and seller typically have gains from trade, because the contract is unlikely to be tailored to induce the buyer to pick $x$ efficiently ex post. These gains from trade are given by $V_{B S}-V_{B}-V_{S}$, which we write as

$$
\begin{aligned}
R_{B S}=\left[v\left(x^{*}, 0, z\right)-c_{S}\left(x^{*}, z\right)\right]- & {\left[v\left(x^{\mathrm{B}}, 0, z\right)\right.} \\
& \left.-f\left(x^{\mathrm{B}}, 0, K\right)\right]-\left[f(\hat{x}, \hat{y}, K)-c_{S}(\hat{x}, z)\right],
\end{aligned}
$$

where $R_{B S}$ stands for renegotiation. For future use, note that

$$
\frac{\partial R_{B S}}{\partial K}=-f_{K}(\hat{x}, \hat{y}, K) .
$$

Using $f_{K x}=0$, this implies, in turn, that for any firm $j$,

$$
\frac{\partial^{2} R_{B S}}{\partial K \partial I_{j}}=-f_{K y} \frac{\partial \hat{y}}{\partial I_{j}} .
$$

Finally, consider $V_{S E}$. Because the entrant cannot produce and sell any positive amount without the buyer's involvement, the only way that $V_{S E}$ could differ from $V_{S}$ would be for the entrant to agree not to 
deal with the buyer, despite mutual gains to trade between $B$ and $E$, as a way of inducing the buyer to buy more from the seller. We assume that this type of agreement is illegal, so $V_{S E}=V_{S}$, as just calculated. We also assume that the entrant cannot serve as a low-cost supplier for the seller, because the entrant's products are differentiated from the seller's and the buyer's approval is needed to make this substitution.

BARGAINING PAYOFFS. We are now ready to express each firm's bargaining payoff in terms of the bargaining parameters (the $\alpha \mathrm{s}$ ), the ex post demand and cost conditions, $z$, and the contractual provisions, $K$. We have

$$
\begin{aligned}
& U_{B}=v\left(x^{\mathrm{B}}, 0, z\right)-f\left(x^{\mathrm{B}}, 0, K\right) \\
& \quad+\alpha_{B}^{S E}\left(\Delta+R_{B S}\right)+\alpha_{B}^{S} R_{B S}+\alpha_{B}^{E} G_{B E}-I_{B},
\end{aligned}
$$

$$
\begin{gathered}
U_{S}=f(\hat{x}, \hat{y}, K)-c_{S}(\hat{x}, z) \\
+\alpha_{S}^{B E}\left(\Delta+R_{B S}-G_{B E}\right)+\alpha_{S}^{B} R_{B S}-I_{S}, \text { and } \\
U_{E}=\alpha_{E}^{B S} \Delta+\alpha_{E}^{B} G_{B E}-I_{E} .
\end{gathered}
$$

Armed with these payoff functions, we can now analyze investment incentives, study the contractual terms that the buyer and seller will adopt, and thus explore the effects of legal restrictions on the allowable contracts. Our analysis is exploratory, in that we examine the marginal incentives of the buyer and seller to utilize penalty clauses, but we do not characterize the fully optimal contract that the buyer and seller would sign, a prerequisite to conducting comparative-statics exercises on that contract as legal rules change.

\section{No Investments}

We begin with the simple but illustrative case in which there are no investment decisions. Without investments and with our standing assumption of ex post efficiency, there are no welfare effects, only renttransfer effects, to explore. Using the expressions above, we have

$$
\frac{d \bar{U}_{E}}{d K}=E_{\theta}\left(\alpha_{E}^{B} \frac{d G_{B E}}{d K}\right),
$$

which can be written as 


$$
\frac{d \bar{U}_{E}}{d K}=-\alpha_{E}^{B} E_{\theta}\left[\frac{\partial f(\hat{x}, \hat{y}, K)}{\partial K}\right] .
$$

To illustrate, suppose that $B$ must make a fixed payment $K$ to $S$ if and only if $y>0$. Then $d U_{E} / d K=-\alpha_{E}^{B}$ if $B$ and $E$ have gains from trade, and zero otherwise.

In this case, there is nothing causing $B$ and $S$ to limit the penalty payment. Holding aside the entrant's investment incentives, the buyer and seller collectively benefit from reducing the entrant's gains from trade with the buyer. A fully exclusive contract completely eliminates such gains.

This result should be contrasted with that of Aghion and Bolton, who find that a finite penalty payment is optimal for the buyer and seller in the absence of renegotiation. ${ }^{22}$ The higher the penalty, the greater the ex post inefficiency in their model, because uncertainty remains about the entrant's costs, as through our $\theta$. With renegotiation, the buyer and seller in their model would have no reason to limit the size of the penalty payment.

We are now ready to look at the impact of penalty clauses in the presence of investments, so that these clauses can do more than merely shuffle around rents. We look in turn at investments by the entrant, the seller, and the buyer. ${ }^{23}$ In all of these situations, it is important to keep in mind that the effects we study operate entirely through the effect of the penalty clause on the parties' threat points, and thus the ex post division of rents, and never through the actual ex post allocation, which is assumed to be efficient, and thus independent of $K$. The ultimate efficiency effects occur because the division of rents alters real investments and thus has real efficiency effects.

\section{Investments by the Entrant}

Suppose that the entrant makes investments, $I_{E}$, which either lower the entrant's marginal cost or raise the marginal value of the entrant's product to the buyer. Using our general results, we know that the

22. Aghion and Bolton (1987).

23. We have not formally studied situations in which multiple firms make investments. To do so requires working with the Nash equilibria of those investment decisions, given $K$. Our analysis can be seen as studying the shifts in the reaction schedules in investment space, and how these investments affect ultimate payoffs. 
presence of entrant investments does not alter our basic result from the no-investment case: the buyer and seller will set excessive penalties, because these penalties reduce the entrant's payoff, that is, they extract rent from the entrant. We can also show that under rather general conditions, penalty clauses not only will harm the entrant, but will specifically lead to a reduction in the entrant's investment. The entrant's optimal investment level, $I_{E}^{*}(K)$, is the solution to

$$
\max _{I_{\ell:}} E_{\ominus}\left(\alpha_{E}^{B S} \Delta+\alpha_{E}^{B} G_{B E}-I_{E}\right) .
$$

Using standard comparative statics methods, the sign of $d I_{E}^{*}(K) / d K$ is the same as the sign of the expected value of $\partial^{2} \bar{U}_{E} / \partial I_{E} \partial K$. Using equation 8 , the sign of $d I_{E}^{*}(K) / d K$ equals the sign of the expected value of $-f_{K y}\left(d \hat{y} / d I_{E}\right)$, where subscripts on $f$ again denote partial derivatives. We know that $\hat{y}$ rises with $I_{E}$, because the entrant's investments raise the marginal value of $y$ to the buyer and thus make it optimal for the buyer to substitute $y$ for $x$. Under our definition of a penalty provision, we also have $E_{\theta}\left(f_{K !}\right)>0$. Together, all this implies that $d I_{E}^{*}(K) / d K$ is negative.

The fact that higher penalties reduce both the entrant's payoffs and investments does not imply that the buyer and seller will want to use arbitrarily high penalty clauses or an exclusive dealing contract. At least in some ranges of $K, B$ and $S$ will face a trade-off: a stricter penalty clause extracts greater rents from $E$, but at the expense of reducing $I_{E}$, which can easily harm $B$ and $S$ collectively. We know that $B$ and $S$ will use excessive penalty clauses, but they may well want to permit some gains from trade in some ex post states between the entrant and buyer to bring forth greater investments by the entrant.

To the extent that they are able, the buyer and seller will design their contract to reduce the gains from trade that the entrant offers to the buyer without reducing the entrant's investment incentives. In other words, they would like to reduce the entrant's average payoff without reducing the entrant's marginal return to investment. This is easier, the less uncertainty is faced by the entrant regarding the terms of trade it will likely offer the buyer. Per-unit penalties can help achieve this objective in some settings.

Do the entrant's investments in fact benefit the buyer and seller collectively? Clearly $I_{E}$ has a direct positive impact on the buyer and 
seller: greater investment by E increases the entrant's social contribution, $\Delta$, of which $B$ and $S$ capture a portion. There are two additional channels by which $I_{E}$ affects $B$ and $S$ together. First, greater investments increase the gains from trade between $B$ and $E$, of which $B$ captures a portion. Second, and for precisely the same reason, greater investments by $E$ can reduce the stand-alone value of $S$.

As elsewhere, our results closely follow those of Segal and Whinston. ${ }^{24}$ They compare two extremes, the null contract to the exclusive contract, and find that exclusivity can lower overall welfare by reducing the entrant's investments. We study specific contractual provisions, which in their limit are equivalent to full exclusivity, and find that a systematic bias toward using these provisions exists in the case where only the entrant makes investments.

Our results also are related to those found in Spier and Whinston. ${ }^{25}$ They too find that the buyer and seller can use socially excessive liquidated damage provisions. Our model differs from theirs in that they have unit demands, while we permit variable demand; we also consider full ex post efficient bargaining, while they focus on two-way renegotiations between the buyer and the seller.

\section{Investments by the Seller}

With seller investments, we must keep track of the term

$$
\frac{\partial \bar{U}_{E} d I_{S}}{\partial I_{S} d K}
$$

in the expression showing the impact of $K$ on the entrant's payoffs. We break the analysis into two parts, depending upon the nature of the seller's investments. First we consider cost-reducing investments by the seller; then we consider value-enhancing investments. These are fundamentally different, for three reasons. First, unless the buyer renegotiates with the seller, cost-reducing investments do not affect the buyer's choice of how much to buy from the seller, because the buyer operates under the terms of the original contract. This is not true of value-enhancing investments. Second, and because of the first factor, value-enhancing investments affect the buyer's demand for the entrant's 
products, and thus the gains from trade the entrant can offer. Third, the seller enjoys direct cost savings from cost-reducing investments but does not benefit from value-enhancing investments unless he renegotiates with the buyer.

COST-REDUCING INVESTMENTS BY THE SELLER. The presence of costreducing investments by the seller provides an additional reason for the buyer and the seller to overuse penalty provisions. ${ }^{26}$ Specifically, we show that $\partial \bar{U}_{E} / \partial I_{S}$ is negative and that $d I_{S} / d K$ is positive, so that the indirect impact on $E$ of a penalty clause is negative, giving the buyer and seller an extra reason to use penalty clauses.

Look first at $\partial \bar{U}_{E} / \partial I_{S}$. Referring back to the expression for $U_{E}$, we must look at the impact of $I_{S}$ on two terms, $\Delta$ and $G_{B E}$. Cost-reducing investments by the seller reduce the entrant's social contribution in any ex post situation, under our standing assumption that $x$ and $y$ are substitutes. In addition, investments by the seller that lower the seller's costs have no impact on the buyer-entrant gains from trade, because the buyer and entrant take as given the terms in the buyer-seller contract, which is not contingent upon the seller's costs, and thus his $I_{S}$. Finally, investments by the seller that raise the value the buyer places on the seller's products reduce the entrant's gains from trade. All of these effects work in the same direction, to lower the entrant's payoff.

Look next at $d I_{S} / d K$. This requires tracing through the impact of $K$ on investment returns to the seller, as reflected in the different terms making up $\bar{U}_{S}$, as shown in equation 13 . Note first that in this case, $G_{B E}$ is independent of $I_{S}$. Consider next $R_{B S}$. We noted above that the sign of $\partial^{2} R_{B S} / \partial K \partial I_{S}$ is the opposite of the sign of $d \hat{y} / d I_{S}$. But we know that $d \hat{y} / d I_{S}=0$, because cost-reducing investments by the seller cannot alter the buyer's optimal choice of $x$ and $y$ in bilateral negotiations with the entrant. We also know that $K$ does not affect the entrant's social contribution, which is a second term in $U_{s}$. Thus, the only route for $K$ to affect $U_{S}$, and thus $I_{S}$, is through the seller's stand-alone payoff, $f(\hat{x}, \hat{y}, K)-c_{S}\left(\hat{x}, I_{S}\right)$.

With cost-reducing investments by the seller, $\hat{x}$ and $\hat{y}$ are independent of $I_{S}$. In this case, the return on investment to the seller through her

26. In a model with "reliance", investments by the seller, with unit demand, and without fully efficient ex post bargaining, Spier and Whinston (1995) show how the buyer and seller may use privately stipulated damages, which we would call penalty clauses, to capture rents from the entrant. 
stand-alone payoff is given by $-\partial c_{S}\left(\hat{x}, I_{S}\right) / d I_{S}$. Assuming that $I_{S}$ reduces marginal costs, this return on investment increases with $K$, because a higher $K$ leads to a higher $\hat{x}$.

We find it interesting that in our model, the seller's investment depends positively upon the penalty, $K$, while one of the main results in Segal and Whinston is that exclusivity does not affect the seller's optimal cost-reducing investments. ${ }^{27}$ The difference arises because we permit the buyer and seller to agree on specific terms of trade, while Segal and Whinston do not. In our formulation, $V_{S}, V_{S E}$, and $V_{B}$ depend upon the contract $f$, and moreover $V_{S}$ depends upon $I_{S}$ for cost-reducing investments by the seller. In contrast, in Segal and Whinston, $V_{S}=V_{B}$ $=V_{E}=V_{S E}=0$, so all of these coalition values are independent of both $K$ and $I_{S}$.

VALUE-ENHANCING INVESTMENTS BY THE SELLER. The analysis is more complex for value-enhancing investments by the seller. Our finding still holds that the entrant's payoff is decreasing in the seller's investment, but it now seems possible, if unlikely, that the seller will invest less if the penalty is higher. With a small penalty, the seller might possibly want to invest to keep the buyer's demand (assuming a marginal price in excess of marginal cost). With a large penalty, the seller may not be in danger of losing the buyer's patronage and thus might invest less. On this argument, the buyer and seller might pick a low penalty clause as a way to induce more investment by the seller, to the entrant's detriment.

Having said this, we must note that the seller's incentives to make value-enhancing investments are quite muted in this model. The fact is, it is all too easy for the buyer simply to appropriate the fruits of those investments by buying under the terms of the original contract. This is the usual problem for a seller improving quality under a fixedprice contract. Worse yet, to the extent that quality is improved, the entrant's social contribution is reduced, and the seller at least stands to gain a portion of that contribution. So, the seller may actually be penalized for improving his own quality.

If the seller's investments are not specific to the $B S$ relationship, that is, if the seller's investments increase the value the buyer places on dealing with the entrant as well, it is harder, or impossible, for the

27. Segal and Whinston (1997). 
seller to reduce the entrant's gains from trade by investing. The seller's investments, however, can now add to the entrant's social contribution, a portion of which accrues to the seller.

\section{Investments by the Buyer}

First, consider investments the buyer makes that increase the buyer's value of dealing with the seller but that do not affect the buyer's value of dealing with the entrant. ${ }^{28}$ It is immediately clear that these investments reduce the entrant's social contribution and the gains from trade that the entrant has with the buyer. These are the two terms that give rise to the entrant's returns from investment. We can conclude that the buyer and seller will have a strategic incentive to induce the buyer to make more of these investments, beyond the point of social return.

The question, then, is whether increasing the penalty clause has such an effect. This depends upon the sign of the cross-partial $\partial^{2} \bar{U}_{B} / \partial I_{B} \partial K$. We know that

$$
\frac{\partial \bar{U}_{B}}{\partial K}=\alpha_{B}^{E} \frac{\partial \bar{G}_{B E}}{\partial K}+\left(\alpha_{B}^{S}+\alpha_{B}^{S E}\right) \frac{\partial \bar{R}_{B S}}{\partial K} .
$$

Differentiating with respect to $I_{B}$, and using our earlier expressions for the cross-partials of $G_{B E}$ and $R_{B S}$ with respect to $K$ and $I_{j}$, the sign of $d I_{B}^{*}(K) / d K$ is the opposite of the sign of $d \hat{y} / d I_{B}$.

For investments specific to the seller, we must have $d \hat{y} / d I_{B}<0$, and thus $d I_{B}^{*}(K) / d K>0$. The buyer has greater incentives to invest in the presence of a larger penalty clause: the penalty will shift the buyer's demand toward $x$ from $y$, making investments in enhancing the value of $x$ more attractive.

We find it interesting that one rationale sometimes given for exclusive contracts, namely, the presence of relationship-specific investments, in fact is a source of their overuse. Penalty provisions and exclusivity are more likely to be justified by the presence of nonspecific investments, which can give rise to free-riding. Concerns about freeriding have in fact been raised by defendants in exclusive dealing cases (including the Nintendo case discussed later).

The analysis of general investments differs from that of specific ones in that the entrant may well benefit from these investments, if the

28. Segal and Whinston (1997) call these "internal investments.", 
"general" component is large enough relative to the "specific" component. This itself would reverse the buyer's and seller's strategic incentives in comparison with the case of specific investments: the buyer and seller would have an incentive to reduce the buyer's investments.

What about the effect of the penalty on the buyer's investments? In this case, a stronger penalty will decrease investment if and only if decreased investments lead to a lower value of $y$. (This is the reverse of the case for specific investments.) Using equation 8 and the analysis just above, the impact of $K$ on $I_{B}$ depends upon the sign of $d \hat{y} / d I_{B}$. With investments specific to the seller, this term is negative. With general investments, however, this term can easily be positive, in which case higher penalties will discourage investment by the buyer.

All this suggests an interesting case that may be important in practice. Suppose that the entrant benefits from the buyer's investments because they have a significant general component. Suppose also that a higher penalty leads to smaller investments because the penalty reduces $y$ and thus the returns on investment. In this case the buyer and seller have a strategic incentive to inflate the penalty, in order to reduce the buyer's general investments and thus harm the entrant. This is distinct from the story above, where the larger penalty harmed the entrant by increasing the buyer's specific investments.

\section{Alternative Models and Assumptions}

Actual trading environments are likely to differ from our stylized model of penalty clauses. For example, our model assumed that all the parties could costlessly engage in efficient ex post bargaining. Clearly, contracts represent far less of a commitment in this world than in a world with costly renegotiation. Thus penalty clauses can be used even more effectively to deter entry if they are hard to renegotiate. ${ }^{29}$ Furthermore, penalty clauses of this sort can cause ex post inefficiency. Similar results are likely to obtain if parties cannot bargain to reach an efficient outcome because, for example, they can only use linear prices. ${ }^{30}$

We have assumed that the seller is in a position to sign a contract

29. This point was demonstrated by Aghion and Bolton (1987).

30. Matthewson and Winter (1987) provide an example of simple contracts that may foreclose efficient entrants. 
with the buyer before the entrant appears on the scene. As noted above, this is eminently reasonable if the entrant is truly not yet in the market, for example, if the entrant is conducting research and development and does not yet even know which set of customers it will be seeking out or what it can offer them. In some circumstances, however, the entrant may be active in the market when the seller seeks to sign a contract with the buyer. If the seller and the entrant are equally well placed to offer contracts to a single buyer at the same time, the entrant is in a much better position to protect itself. The use of exclusive dealing provisions to inefficiently exclude entrants can depend very much on the presence or absence of a first-mover advantage. ${ }^{31}$ Thus, antitrust policy should distinguish between a patent holder with a strong monopoly position signing contracts with buyers before any entry and a patent holder engaged in active competition with substitute technologies and products.

A key assumption in our analysis is that the seller deals with only a single buyer. With many buyers, a single incumbent seller can adopt a "divide-and-conquer" strategy, using penalty clauses or exclusive dealing provisions that can effectively exclude would-be entrants. Indeed, with many, uncoordinated buyers, this strategy can be especially profitable. ${ }^{32}$

The key point is that an exclusive dealing provision or a penalty clause with one buyer can impose a negative externality on other buyers by reducing either the probability or the magnitude of entry. If many buyers have signed such contracts, each regards the probability of entry as slim or nonexistent and is willing to agree to be exclusive to the seller, or to pay a stiff penalty for turning to another supplier, in exchange for a modest sweetener. Individually, each buyer can easily be induced to sign such an agreement. Collectively, they are worse off as a result. ${ }^{33}$ This divide-and-conquer strategy can be seen in several of the cases reported below, including arguably the Microsoft case and the Nintendo case.

31. This has been shown by Bernheim and Whinston (1996).

32. The strategic use of exclusive dealing contracts to deter entry in the presence of multiple buyers was recognized clearly by Aghion and Bolton (1987), who cite Salop (1986) on this point as well.

33. This point was further developed in Rasmusen, Ramseyer, and Wiley (1991) and refined by Segal and Whinston (1996). 
In practice, we believe that penalty clauses are most worrisome in the combined presence of multiple, uncoordinated buyers and substantial scale economies. Similar reasoning indicates that the dangers associated with exclusive dealing provisions in the presence of multiple, uncoordinated buyers are especially great in markets subject to strong demand-side scale economies, that is, network externalities. In such markets commitments by today's buyers to patronize the incumbent seller and agreements that raise their costs of switching to alternative suppliers can be especially effective in deterring entry by incompatible technologies.

\section{Economic Theory and Antitrust Policy for Licensing Arrangements}

We are now ready to review several specific licensing practices that have attracted scrutiny under the antitrust laws and to discuss the economic implications of these practices. These include several of the Nine No-No's of patent licensing, as well as several other practices that have been challenged by the antitrust authorities. We begin by focusing on licenses that contain exclusive dealing provisions, applying the general theory described in the penalty section.

\section{Exclusive Dealing}

The clearest form of exclusive dealing arises when the license contains an outright prohibition on the licensee engaging in commerce with other technologies; this is de jure, or explicit, exclusivity. Other provisions, such as minimum commitments by the licensee or penalty payments imposed on the licensee if he uses alternative technologies, may have the same economic effect. The IP guidelines note that "Such restraints may anticompetitively foreclose access to, or increase competitors' costs of obtaining, important inputs, or facilitate coordination to raise price or reduce output. . . ', The guidelines also note, however, that such restraints may have pro-competitive effects. ${ }^{34}$ We now

34. DOJ and FTC (1995, p. 20). Both the Supreme Court, in Tampa Electric Co. v. Nashville Coal Company, 365 U.S. 320 (1961), and the FTC, in the matter of Beltone Electronics Corp., 100 F.T.C. 68 (1982), endorsed a full rule-of-reason inquiry into exclusive dealing provisions. 
discuss some recent government and private antitrust cases involving intellectual property and exclusive dealing.

U.S. v. MICROSOFT. In 1990 the FTC initiated an investigation of competitive practices by the Microsoft Corporation. The impetus for the investigation was an alleged agreement between Microsoft and IBM over the development and marketing of their Windows and OS/2 operating systems. That agreement soon became moot as Microsoft and IBM went their separate ways, but the FTC expanded its investigation to consider other competitive conduct by Microsoft, including Microsoft's use of its market power in personal computer (PC) operating systems to gain an advantage in application programs and its licensing practices with original equipment computer manufacturers (OEMs) and computer distributors. In 1993 the FTC staff recommended that the commission issue a complaint against Microsoft focusing on its licensing arrangements with OEMs and distributors, which staff alleged coerced Microsoft's customers to purchase its products. The commission, however, deadlocked in a 2-2 vote (with one commissioner recused), so no case was brought.

The Antitrust Division of the Department of Justice took up where the FTC had left off. The division's investigation was far-reaching, but ultimately focused on Microsoft's practices in the licensing of its MSDOS and MS-Windows operating system products.

On July 14, 1994, the division brought a complaint against Microsoft alleging that the company unlawfully maintained its monopoly of PC operating systems and unreasonably restrained trade by using exclusionary license agreements with OEMs and by requiring developers of independent applications to sign onerous nondisclosure agreements. The division identified several aspects of the OEM licenses that were objectionable. One was the use of "per-processor" contracts, which required OEMs to pay Microsoft a fee for every computer system that they sold, without regard to whether the system included a Microsoft operating system. In addition, the division objected to Microsoft's use of long-term contracts with large minimum commitments by the OEMs.

Economic theory and specifically our analysis of penalty clauses provide a basis for concern about the competitive consequences of Microsoft's licensing practices. A long-term contract is similar in some respects to an exclusive dealing arrangement. Although the former does not prevent the licensee from doing business with others, the commit- 
ment to deal with the licensor reduces the gains from trade with other licensors. With the long-term contract in place, other licensors can bargain only over the incremental benefit that they can offer to the licensee. The deterrent effect of Microsoft's long-term contracts was compounded by the fragmented nature of the market for computer manufacturing and distribution. The personal computer OEM market has several buyers who, although influenced by common economic incentives, make independent choices about how to configure the machines that they manufacture. Thus, the market for sales of PC operating systems to OEMs is susceptible to monopolization by a dominant supplier. ${ }^{35}$ Each long-term contract with the dominant supplier of operating systems makes the entry of a new operating system more difficult. In the presence of various scale economies and network externalities, entry may be foreclosed when a large number of OEMs accept long-term contracts, especially if these contracts are staggered.

Other factors reinforce the competitive concerns about Microsoft's licensing practices. Microsoft is clearly the dominant supplier of operating systems for IBM-compatible PCs and thus can exercise market power in determining licensing terms. Moreover, Microsoft enjoyed a significant first-mover advantage in licensing operating systems. In the time period examined by the FTC and the Antitrust Division, Microsoft faced actual competition from Digital Research's text-based operating system (DR-DOS) and potential competition from IBM's OS/2, but Microsoft was already firmly established as the supplier of operating systems to OEMs. These facts are consistent with our stylized model of penalty clauses, which assumes a single seller with a first-mover advantage in negotiating a contract with its licensee. An additional important factor in the Microsoft case that is not considered in our model is the role of network externalities, which generally make it difficult for entrants to establish new operating systems in the market and may reinforce the exclusionary aspects of Microsoft's contracts.

Of course there are pro-competitive reasons for the use of long-term contracts with minimum commitments. Such contracts reduce the uncertainty of demand and thus may promote investment by the licensor. A long-term contract with a minimum commitment also reduces the

35. This monopolization is described by Rasmusen, Ramseyer, and Wiley (1991) and Segal and Whinston (1996). 
incentive for the licensee to act opportunistically and to exploit the value of the licensor's investments through trade with other suppliers. Moreover, even if Microsoft's contracts had the effect of committing existing OEMs to use only Microsoft's products, this would not prevent the entry of competing operating system products if the minimum efficient scale of entry for a new OEM that specializes in an alternative operating system (such as Apple) is sufficiently small.

The Antitrust Division and the FTC staff concluded that the potential benefits from Microsoft's long-term contracts did not outweigh the risk of competitive harm. The argument that Microsoft needed long-term contracts with large minimum commitments to prevent licensees from free riding on Microsoft's investments was not compelling. The growth of large computer manufacturers and retailers such as Compaq, Packard Bell, Hewlett-Packard, and Dell suggests that although the OEM industry is not highly concentrated, the efficient scale of entry also is not small. A requirement that a vendor of a new operating system (such as $\mathrm{OS} / 2$ ) enter the market by investing in a new OEM that is specialized to that operating system would raise a significant barrier to entry with little offsetting efficiency gain.

Microsoft's use of the "per-processor" contract raises less familiar issues, but these issues can be addressed using the methodology we discussed in the penalty section. The per-processor contract is a "takeor-pay" contract of the following form. For each computer that it sells, the OEM can choose to supply the computer with the Microsoft operating system for a price, $p$. If the OEM chooses not to use the Microsoft operating system, it pays a "penalty price,"' $K$. Thus, the contract can be described by $f(x, y, K)=p x+K y$, with $K=p$. This is a contract in which the cost to the buyer of the seller's product is an increasing function of the amount that the buyer purchases from a different seller.

Let $v$ be the per-unit value to the OEM from purchasing the Microsoft operating system, and let $w$ be the per-unit value of an alternative operating system (derived from the retail prices that the OEM can command for the correspondingly equipped machines). The use of the alternative operating system is socially optimal if, and only, if

$$
w-c_{E}>v-c_{M},
$$

where $c_{M}$ and $c_{E}$ are the incremental costs of the Microsoft and alternative operating systems. 
Assuming sophisticated agents, bargaining should ensure that an OEM will employ an alternative operating system if it indeed offers greater potential surplus for consumers and thus can command higher retail prices. Under the per-processor contract, the coalition consisting of the OEM and the entrant have gains from trade, namely, the OEM and entrant collectively would benefit from the OEM's using the entrant's operating system without renegotiating its contract with Microsoft, if and only if

$$
w-c_{E}-K>v-p .
$$

The analysis in the penalty section shows that Microsoft and each OEM taken in isolation have a joint incentive to agree to a contract that penalizes sales by alternative suppliers of operating systems. The term $K$, which equals $p$ in the per-processor contract actually employed by Microsoft, reduces the gains from trade between the OEM and the entrant and thus reduces the surplus that the entrant may appropriate.

With efficient bargaining ex post, the welfare consequences of the penalty act through its effect on investment incentives. The penalty will reduce alternative suppliers' investment incentives and reduce the OEM's incentive to invest to the extent that its investments would be likely to benefit suppliers of alternative operating systems. ${ }^{36}$

The Department of Justice complaint also alleged that Microsoft interfered with competition by imposing excessive nondisclosure requirements on independent developers of application software programs. The success of an operating system depends on the application programs that will run under the control of that system. Both Microsoft and independent software developers have an interest in cooperating during the development (beta-test) stage of the operating system. Microsoft benefits by expanding the number of compatible application programs, and independent software vendors benefit by having a head start in the release of their products.

There is a legitimate role for nondisclosure agreements. Microsoft cannot involve application writers in its beta test without disclosing some confidential information about the structure and design of its product. Microsoft's nondisclosure agreements in connection with its

36. A defense of the per-processor contract is that it discourages OEMs from selling machines with no operating system at discounted prices, which are then targets for pirated software. 
Windows 95 beta test, however, prevented at least some independent software developers from working with competitors of Microsoft for more than one year, which can seem like an eternity in the fast-paced computer industry. Microsoft's nondisclosure agreements had the effect of encouraging application developers to be exclusive to the Microsoft operating system by imposing high costs on developers who would choose to write programs for another system. The theory of penalty clauses is applicable to Microsoft's nondisclosure conditions. We discuss this application in more detail in the context of the Atari v. Nintendo case.

ATARI v. NINTENDO. In the late 1980s Atari Corporation sued Nintendo for monopolizing the market for video game systems. Each system consists of hardware consoles and compatible game cartridges. At the time of the suit, Nintendo was the dominant supplier of video games, with approximately 80 percent of total console sales. The key practice at issue in the suit was Nintendo's use of exclusive contracts, which required a game developer seeking to offer a game for play on the Nintendo system to agree not to make a version of that game for any other video game system for a two-year period. Nintendo enforced its exclusivity provision by using a "lock-out chip,"' which prevented unauthorized games from playing on the Nintendo game console. Because of the lock-out chip, game developers required a license from Nintendo to make games for the Nintendo system.

Nintendo's exclusivity provision had a competitive effect on suppliers of competing games similar to the effect of Microsoft's nondisclosure conditions. It raised the cost to independent game developers of supplying games to Nintendo's competitors, Atari and Sega: doing so would require that they forsake the far larger Nintendo-installed base of machines, at least for a two-year period during which most games made the bulk of their sales, after first appearing in arcades.

In the framework of our stylized model, Nintendo is a licensor of intellectual property (the codes necessary for games to play on Nintendo machines) that game developers require to gain access to the Nintendoinstalled base of users. Nintendo licenses its intellectual property to game developers, each of whom plays the role of the buyer or licensee in our model. These licensees may deal subsequently with other technology licensors, such as Atari or Sega, but Nintendo enjoyed a firstmover advantage in the revived video game market around 1985. Based 
initially on its first-mover advantage and later on strong network externalities and the presence of multiple, uncoordinated game developers, Nintendo and each individual game developer, as in our model, had mutual incentives to include penalty clauses in their contracts that reduce the gains between game developers and the other licensors, Atari and Sega. As a result, Nintendo's exclusivity requirement had the effect of reducing specific investments in games for the Atari and Sega systems. The key investments in this case were those necessary to convert hit arcade games over to the Atari and Sega systems. ${ }^{37}$

Atari argued that Nintendo's exclusive licensing contracts with game developers reduced competition from Nintendo's rivals by making it costly or impossible for them to offer the hit games on their own systems. Nintendo argued that there was an ample supply of games, that the exclusives were justified by investments Nintendo made to promote the games, and that Atari's difficulties in the market did not stem from the exclusive contracts. ${ }^{38}$

U.S. v. GENERAL ELECTRIC. In August 1996 the Department of Justice filed an antitrust complaint against General Electric alleging that GE violated the Sherman Act by entering into restrictive licenses with hospitals for its high-tech medical imaging equipment. The licenses authorized the hospitals to use advanced GE diagnostic software to service their own GE medical imaging equipment and also required them not to compete with GE in servicing any other facilities' medical equipment, including non-GE equipment. The government alleged that the license restriction constituted a per se violation of the Sherman Act by GE.

37. In our model the licensor must make a sufficiently attractive offer to induce the licensee to accept the penalty provision in the contract. Nintendo did indeed share some of the rents with developers of hit games, especially early on before Nintendo's installed base became dominant. This rent sharing led to a legal issue of whether game developers were "victims" or "co-conspirators," who were involved in a "conspiracy" with Nintendo to exclude rival systems from the market. As a general matter we presume that any licensee who signs a license containing a penalty clause receives sufficient compensation to accept the constraints imposed by the clause. Thus we are unsure how one could make an economically meaningful distinction between a "victim" and a "coconspirator." We are more interested in whether those provisions are collectively harmful to licensees or to entrants, and ultimately to final customers, in this case consumers of video game systems, who are not themselves licensees.

38. Shapiro served as an expert witness for Atari. The jury hearing this case found a lack of causation between Nintendo's practices and Atari's difficulties in the market. 
The government argued that hospitals, which often have their own internal service organization, are actual and potential competitors of GE in the servicing of sophisticated medical imaging equipment. According to the Justice Department, GE's license eliminates this source of competition. GE's license could also harm interbrand competition in markets for systems of medical equipment and service by eliminating an efficient servicer of non-GE equipment and thus raising the total cost of ownership for non-GE brands of equipment.

The economic theory of this arrangement is complicated by the fact that General Electric and its customers sell and consume complementary services. General Electric sells medical imaging equipment and provides diagnostic services for this equipment. In addition, GE may benefit, through enhanced demand for its equipment sales, from diagnostic services provided by its customers. GE's customers consume GE's equipment. They may also consume diagnostic services from GE and may compete with GE as suppliers of diagnostic services for their own machines and machines owned by third parties and for GE-brand machines as well as other brands of machines. The general theory of penalty clauses is applicable here. To the extent that GE and its customers bargain independently of other equipment manufacturers, GE has an incentive to impose a penalty that discourages its customers from dealing with other manufacturers, and its customers have an incentive to accept that penalty. The analysis is further complicated, however, by the complex complementary relationships that exist in this market.

\section{Territorial and Field-of-Use Restrictions}

Territorial and field-of-use restricted licenses are generally acceptable under the principle that the owner of intellectual property may grant limited licenses or no license at all. Such restricted licenses can be used to give the licensee exclusive rights to a geographic territory or field of use. Exclusivity can protect the licensee from free-riding by other licensees or the licensor and thus may increase the licensee's incentive to invest in the licensed technology. Restricted licenses also may increase the licensor's incentive to license, for example, by protecting the licensor from competition in a market that it prefers to keep to itself. ${ }^{39}$ Note that an exclusive license does not necessarily prevent a

39. DOJ and FTC (1995). 
licensee from transacting with suppliers of other technologies and thus need not raise the competitive concerns addressed in exclusive dealing arrangements.

Territorial and field-of-use restrictions run afoul of the antitrust laws if they are employed in a manner that creates or facilitates cartel activity. The Department of Justice has challenged several licensing arrangements on this theory in the past. ${ }^{40}$ More recently it filed a complaint against the Pilkington Company alleging that Pilkington's licenses sustained a worldwide cartel in the manufacture and sale of flat glass. ${ }^{41}$

Pilkington developed the revolutionary float glass process in the 1950s, which uses a molten metal bath to produce large continuous sheets of flat glass. The float glass process has since become the dominant technology worldwide for the manufacture of flat glass. Pilkington entered into patent and know-how licenses that restricted the use of its float technology and the sale of some glass made with its technology to specific territories. Pilkington's know-how licenses remained in force long after the patents expired.

The Department of Justice alleged that Pilkington monopolized the world market for the design and construction of float glass plants through licensing arrangements that allocated and divided territories for, and limited the use of, float glass technology worldwide. ${ }^{42}$ In effect, the government complained that Pilkington had acted as a "cartelmeister," using territorial and other restrictions to sustain a monopoly outcome.

Under the government's cartelmeister theory, Pilkington's licensees originally accepted restricted patent and trade secret licenses that pre-

40. See, for example, U.S. v. Sterling Drug Inc. (D.N.J., Civ. No. 175-68, filed February 23, 1968) challenging restrictions on bulk sales of pharmaceutical products (settled with consent decree). Another example is U.S. v. Ciba-Geigy Corp., 508 F.Supp. 1118 (D.N.J. 1976), in which the government alleged that Ciba-Geigy employed use-restricted licenses and postsale restrictions to prevent the sale of a patented drug by generic manufacturers.

41. This case was settled by a consent decree. Gilbert was deputy assistant attorney general when the Justice Department filed its complaint against Pilkington. Shapiro served as an expert witness for Pilkington in an arbitration proceeding between Pilkington and PPG over Pilkington's licensing practices.

42. See U.S. v. Pilkington, Competitive Impact Statement, Civil Action No. 94345, May 25, 1994. The Department of Justice also alleged that Pilkington engaged in various conduct that made it more difficult for firms to compete using technology that Pilkington did not own. 
vented competition in the new float glass technology. By itself, this does not violate the principles described in the IP guidelines, because the licensees would not be actual or potential competitors in the new technology in the absence of a license from Pilkington. Central to the government's theory, however, was the assertion that horizontal competition among Pilkington's licensees would have been stronger without these licenses, once Pilkington's patents expired.

To see how this theory works, suppose that no trade secrets remained after the patents expired. Nothing would then prevent Pilkington's various licensees from attacking each other's (previously exclusive) territories. Were Pilkington, in this situation, to coordinate an agreement among all of its licensees to refrain from such competition, such conduct would be nothing more than an anticompetitive horizontal cartel employing territorial allocations. The Justice Department's position was that Pilkington was effectively doing just this, using its trade secrets as a cover for the cartel. With small numbers of licensees, each could reason that it is more profitable to sustain monopoly prices using the restricted licenses than to risk marketwide competition by challenging the validity of the trade secrets or attempting to use an alternative technology. In this way the licenses could eliminate competition that would have taken place in the absence of the license, one of the key tests enunciated in the IP guidelines. ${ }^{43}$

\section{Tying Arrangements}

In the context of a licensing arrangement, a tie exists when a licensor conditions the grant of a license upon the acquisition of some separate article of commerce. Legal precedent holds that tie-ins of two separate products or services are per se unlawful when the seller has sufficient economic power in the tying product to restrain competition in the tied product market and when a not insignificant amount of interstate commerce is affected..$^{44}$

43. Pilkington vigorously disputed the government's contentions, asserting that its remaining trade secrets were considerable and that it had every right to enforce them worldwide. In any event the cartelmeister theory enunciated in the Pilkington case by the Justice Department could not support PPG's private claim that Pilkington excluded PPG from the market with worthless trade secrets. Under the cartel theory, a firm that is not a member of the cartel would benefit from its formation.

44. Northern Pacific Railway Co. v. United States, 356 U.S. 1 (1958). This legal 
A tie-in may be an explicit requirement to purchase the tied product or may be achieved indirectly by financial inducements. For example, a licensor may charge a nominal royalty for the tying product if licensees also purchase unpatented supplies and a much higher royalty to those who purchase the supplies elsewhere. The economic implications of an explicit tie-in and an indirect price-induced tie-in are similar. Case law also treats both types of tie-ins similarly. ${ }^{45}$

A package license is the granting of a license under one patent (or copyright) conditional on the acceptance of another, different license. Package licensing is formally similar to a tied sale, at least if the second license generates separate royalty payments and if the second technology is not used in fixed proportions with the first. A leading case is Zenith Radio Corp. v. Hazeltine Research Inc., which prohibited Hazeltine from "conditioning directly or indirectly the grant of a license . . . under any domestic patent upon the taking of a license under any other patent." 46 Another key case is U.S. v. Loew's Inc., in which the Supreme Court held that block booking of copyrighted feature motion pictures for television exhibition was an illegal tying agreement. ${ }^{47}$ The complaint was that copyright holders conditioned the license or sale of one or more feature films upon the acceptance by the station of a package or block containing one or more unwanted or inferior films. This ruling included a prohibition on offering a discount for a feature film when sold or licensed with other films if the effect of this discount was to condition the sale or license of the film on the purchase of others. Very similar issues come up under "full line forcing," whereby a manufacturer requires a distributor, say, to carry its full line in order to get some individual products that are in high demand.

In practice, there are several defenses to allegations of illegal tying. One is that the licensor does not possess market power in the tying

formulation has led to endless wrangling over whether two items, such as cars and car radios, are separate products, in which case selling them together can constitute tying, or merely two pieces of a single product, in which case there can be no tying.

45. Ansul Co. v. Uniroyal, Inc., 306 F.Supp. 541 (S.D.N.Y. 1969), 448 F.2d 872 (2d Cir. 1971).

46. Zenith Radio Corp. v. Hazeltine Research Inc., 395 U.S. 100 (1969), at 13334.

47. United States. v. Loew's Inc., 371 U.S. 38 (1962). A similar case was United States v. Paramount Pictures, Inc., 334 U.S. 131 (1948), which dealt with block booking into movie theaters. 
product. Another is that the tying and tied products are not distinct products or that there are compelling efficiency reasons for purchasing them both from the licensor. Package licenses often raise additional defenses. A package license is sometimes necessary if the package includes patents whose use would be blocked if the licensee did not have rights to practice other patents included in the package. Package licensing is also convenient in circumstances in which the licensor and the licensee find it difficult to agree on royalties for individual components of the package and when usage of the individual components is difficult to assess and monitor.

Tied sales raise no competitive issues in many circumstances and often have efficiency justifications. A tied sale may be used to enhance price discrimination by compelling the purchase of a staple product (such as punchcards or paper) that the seller can use to meter a buyer's demand. Such a practice need not be harmful in a licensing context. To the contrary, metering can increase the rent extracted by the licensor and thus further reward innovation, with no incremental deadweight loss. Practices that reward innovators without causing deadweight loss ex post are a poor target for antitrust prohibition. ${ }^{48}$

In other circumstances, a tie-in can adversely affect welfare. For example, Whinston has shown that tying may lead to foreclosure in imperfectly competitive markets. ${ }^{49}$ Tying affects the reaction function of the firm that engages in the tied sale. This effect can commit the firm to be a more aggressive competitor, thus leaving a smaller market share available to a new entrant and ultimately deterring entry.

Formally, a tie can operate much like an exclusive dealing contract, and our previous analysis of exclusive dealing arrangements can be applied to license agreements involving tie-ins. A tied sale provides a mechanism for the seller to structure an exclusive dealing arrangement: the mechanism is a higher price for the tying product if the buyer purchases the tied product from another seller, or equivalently a discount for the tying product if the buyer agrees to purchase both products from the seller. A tie-in also promotes an exclusive dealing arrangement by giving a seller who has market power in the tying product a convenient first-mover advantage to engage in an exclusive dealing contract

48. This point is emphasized by Kaplow (1984).

49. Whinston (1990). 
with the buyer with respect to purchase of the tied product. As with exclusive dealing, the private incentive for the licensor and the licensee to agree to a tie-in exceeds its social value in many circumstances; that is, the licensor and the licensee have too great a mutual incentive to agree to a tying arrangement that excludes competition.

The IP guidelines addressed concerns associated with tied sales in the context of IP licensing. The guidelines state that "In the exercise of their prosecutorial discretion, the Agencies will consider both the anticompetitive effects and the efficiencies attributable to a tie-in. The Agencies would be likely to challenge a tying arrangement if: (1) the seller has market power in the tying product, (2) the arrangement has an adverse effect on competition in the relevant market for the tied product, and (3) efficiency justifications for the arrangement do not outweigh the anticompetitive effects.",50

This language represents a significant shift from legal precedent regarding tied sales. The courts required only that the seller have sufficient market power to "restrain" competition in the tied product market. The IP guidelines require a showing that the arrangement actually has an adverse impact in the relevant market for the tied product. Furthermore, the guidelines include an explicit weighing of efficiencies and anticompetitive effects. Thus, the guidelines evaluate tying arrangements involving intellectual property under the rule of reason, rather than submitting them to the per se rule (albeit a per se rule with various defenses). This approach is consistent with economic theory, which demonstrates that the competitive effects of tying arrangements depend on their particular factual circumstances. The guidelines are not statutory and are not binding on the courts, but relate only to Justice Department and FTC policy with regard to the agencies' prosecutorial discretion. If the agencies choose to litigate an IP tying case, they are likely to follow earlier legal precedent to establish their burden of proof. Nonetheless, the prosecutorial policy described in the IP guidelines sends an important message to the courts and private litigants regarding the agencies' view of the proper standard for evaluating licensing arrangements with tie-ins.

50. DOJ and FTC (1995, pp. 26-27). Elsewhere, the IP guidelines state that "the Agencies do not presume that intellectual property creates market power in the antitrust context'" (Section 2, p. 2). 
Broad Royalty Bases

A licensor may require that royalties be assessed on sales or purchases of goods or services that are not covered by the licensor's intellectual property. The Microsoft per-processor license was a case in point. The OEM was obligated to pay royalties based on the number of computer systems that the OEM sold, rather than on the OEM's use of Microsoft's licensed software. The courts have recognized that permitting royalties to be assessed on sales other than sales of licensed products or technology sometimes facilitates economic efficiency. Sales of patented products may be difficult to observe, yet may be closely correlated with observable sales of other products. Permitting royalties to be based on the observable sales allows the royalty to vary with demand for the licensed intellectual property, which promotes efficient licensing. The Supreme Court has held that "If the convenience of the parties rather than patent power dictates a percentage-of-total sales royalty provision there is no misuse of the patents. ${ }_{51}$

Courts, however, have held that royalties not related to sales of patented products are a misuse of the patent grant when the arrangement is forced upon the licensee. In Zenith Radio $v$. Hazeltine Research, the Supreme Court stated that "patent misuse inheres in a patentee's insistence on a percentage-of-sales royalty, regardless of use, and in his rejection of licensee proposals to pay only for actual use." The Court cited approvingly the District Court's statement that "While parties in an arm's-length transaction are free to select any royalty base that may suit their mutual convenience, a patentee has no right to demand or force the payment of royalties on unpatented products." The Court thus drew a sharp distinction between a situation where the licensor and the licensee agree to use a broad royalty base and one where "the patentee refuses to license on any other basis and leaves the licensee with the choice between a license [with royalties on noninfringing products] and no license at all., ${ }_{52}$

Relying on a distinction between "voluntary" agreements and "coercion" raises severe problems for coherent economic analysis. As we have shown, buyers and sellers may voluntarily enter into licensing

51. Zenith Radio v. Hazeltine Research Inc., 395 U.S. 100 (1969) at 138.

52. Zenith Radio v. Hazeltine Research Inc., 395 U.S. 100 (1969) at 139, 134, 135. 
arrangements that have adverse consequences on competition and on overall economic welfare.

The royalty base is of no consequence if the product whose sales are the basis for royalty calculations is used in fixed proportions with the patented product. The choice of the royalty base, however, can affect profits and economic welfare with only modest departures from fixed proportions. The Microsoft per-processor contract is an example. Operating systems are used in fixed proportions with PC hardware systems, but Microsoft operating systems are not necessarily used in fixed proportions with hardware.

We have shown above that under some conditions, this type of royalty contract can have adverse consequences for economic welfare. Charging royalties based on a final product (such as a computer system) allows the licensor to monitor the licensee's intensity of demand without charging a royalty that would distort the licensee's mix between the licensed product and other inputs. Although this ability is efficiency enhancing, a contract that bases royalties on total sales may harm economic welfare by inefficiently reducing incentives for investment in substitute technologies.

\section{Extension of the Term of IP Protection}

The law clearly holds that the owner of intellectual property cannot charge royalties over a period that exceeds the legal term of protection for that property. For example, in Brulotte v. Thys Co. the owner of various patents for hop-picking sold patented machines and charged a royalty per pound of dried hops harvested by the machine. The contracts required royalty payments to continue after all the patents expired, and the licensee refused to pay. The Supreme Court held that "whatever the legal device employed a projection of the patent monopoly after the patent expires is not enforceable." The Court further stated that "The contracts are, therefore, on their face a bald attempt to exact the same terms and conditions for the period after the patents have expired as they do for the patent period." The Court concluded that to collect such royalties was to "enlarge the monopoly of the patent" in a manner analogous to a patent tying arrangement. ${ }^{53}$ This doctrine has been reaffirmed since by circuit courts, which have held that agreements in-

53. Brulotte v. Thys Co. 379 U.S. 29 (1964) at 32, 33. 
volving unchanged royalties after patent expiration are per se unlawful. ${ }^{54}$

Economic theory reveals that this doctrine is flawed. Clearly, the per-unit royalty that a licensee will accept is a function of the term over which the royalty must be paid. Permitting royalties to be paid over a longer term can, under reasonable conditions, reduce the deadweight loss from a patent monopoly. ${ }^{55}$ Thus, allocative efficiency considerations should permit a licensor and licensee to agree to longer royalty terms. Legal reasoning here, based on the notion that extending the royalties in time is to "enlarge the monopoly of the patent," although rhetorically appealing, does not seem to reflect commercial reality or basic economics.

In many cases patent holders can structure their licenses to get around this inefficient legal restriction. A common tactic is to use a combination of patent and know-how licenses to extend the effective term of the license beyond the patent term, relying on the fact that trade secrets have an indefinite lifetime. (They lose their protection when the information is no longer secret, not at any fixed date.) To see how this strategy works, consider a patent that is worth $v_{1}$ per unit and knowhow that has a value $v_{2}$, when used in conjunction with the patent, where $v_{2}<<v_{1}$. Suppose the license includes a royalty of $v_{1}$ for the duration of the patent and $v_{2}$ for the effective life of the know-how. The high royalty of $v_{1}$ would incur the usual deadweight pricing loss. Suppose instead that the license specified a constant royalty rate greater than $v_{2}$ and less than $v_{1}$, with the same present value. The usual convexity assumptions would imply a lower deadweight loss with this intermediate royalty charged over a longer period of time. ${ }^{56}$ Thus, although the license agreement may appear to extend the duration of the patent license, its effect is to allow that licensor to recover the same present value royalties, but with a lower social cost.

54. See, for example, Meehan v. PPG Industries, Inc. 802 F.2d 881 (7th Cir., 1986) and Lasercomb America, Inc. v. Job Reynolds 15 U.S.P.Q. 2d 1846 (4th Cir., 1990) (holding that requiring royalties to be paid after the seventy-five year copyright term was copyright misuse). The Supreme Court did uphold a contingent contract, signed when a patent application was on file but before the patent issued, calling for the licensee to pay royalties even if the patent did not issue (but greater royalties if it did issue). See Aronson v. Quick Point Pencil Co., 440 US 257 (1979).

55. Gilbert and Shapiro (1990).

56. Gilbert and Shapiro (1990). 
This tactic is not without its own limitations. On the legal side, a constant royalty rate itself may be attacked as lacking a "step-down" provision upon the expiration of the patent. An alternative, perhaps safer, approach would be to collect royalties in excess of $v_{2}$ after the patent expires and somewhat higher royalties during the lifetime of the patent. On the economic side, this licensing arrangement may pose a risk for the licensee if it is not widely applied to its rivals. The risk is that after the expiration of the patents, the licensee would be stuck paying royalties for know-how that exceeds its value. This could make the licensee uncompetitive unless its rivals have similar licensing agreements. Therefore, the tactic may fail unless the patentee is able to sign licenses with most or all industry participants and unless there are some barriers to entry to prevent new firms not subject to the trade secret licenses from taking over the market after the patent expires.

\section{Grantbacks}

A grantback is a licensing provision that obligates the licensee to provide the licensor with rights to some of the licensee's intellectual property, usually patents developed by the licensee that work in conjunction with the licensed technology (the base technology). A grantback provision provides a means for the licensor and licensee to share risks in the development of new technology. The licensor is assured of a share of the value created by new incremental enhancements to the base technology. A grantback may be nonexclusive or exclusive, that is, it may or may not permit the licensee to license its improvements to others.

If the licensor cannot appropriate the value of the enhancements, there may be insufficient incentives to invent technologies that provide a base for valuable enhancements ${ }^{57} \mathrm{~A}$ grantback provision ensures that the licensor will obtain a share of the value of improvements to the base technology. It also ensures that the licensor is not precluded from effectively competing because the licensor would infringe improvement patents. Thus, grantbacks may promote both innovation and the licensing of the results of innovation.

Grantbacks can raise antitrust concerns, particularly if they are exclusive. A grantback provision that requires the licensee to assign to

57. Scotchmer (1991); Green and Scotchmer (1990). 
the licensor all intellectual property rights related to the technology (an "assign-back") may dampen licensee incentives to invent, although these concerns clearly have to be weighed against the increased incentive for innovation by the licensor in the first place. A grantback of an exclusive, royalty-free license is similar to an assign-back, but it permits the licensee to practice the technology.

A grantback provision is unlikely to harm competition unless it stifles innovation. That would require the grantback to be applied in such a manner that it affects a large fraction of the capacity to innovate in an industry. Such concerns are likely to be magnified if the licensor is currently the dominant source of future innovations and if the grantback is likely to sustain that dominant position. In situations where the licensor and licensee are not actual or potential rivals in innovation markets, however, antitrust concerns should be minimal: if they conduct complementary innovation, the licensor would have no incentive to stifle innovation by the licensee.

The Supreme Court has approved the use of a grantback provision in a license and endorsed a rule-of-reason approach to evaluating the effects of grantbacks. ${ }^{58}$ Since then, the lower courts have developed a sensible list of factors to consider in evaluating the effects of grantbacks, including (1) whether the grantback is exclusive or nonexclusive; (2) if exclusive, whether the licensee retains the right to use the improvements; (3) whether the grantback precludes, permits, or requires the licensor to grant sublicenses; (4) whether the grantback is limited to the scope of the licensed patents or covers inventions that would not infringe the licensed patent; (5) the duration of the grantback; (6) whether the grantback is royalty free; (7) the market power of the parties; (8) whether the parties are competitors; and (9) the effect of the grantback on the incentive for developmental research. ${ }^{59}$

We draw a sharp distinction between retrospective grantbacks and prospective grantbacks, which we have heard called "grantforwards." Grantbacks that apply only to existing intellectual property are more akin to royalty-free cross-licenses. We have trouble seeing how these can harm competition or stifle innovation. They would typically appear to reflect the relative strengths of the two parties' patent portfolios.

58. Transparent-Wrap Machine Corp. v. Stokes \& Smith Co., 329 U.S. 637 (1947).

59. This list is taken from Section of Antritust Law (1997). 
Clearly, competition is enhanced if $A$ licenses its patents to $B$ at a royalty rate $r$ and receives a royalty-free license to $B$ 's existing patents as part of the deal, rather than having $A$ license to $B$ at $r+s$ and $B$ license its patents back to $A$ at the rate $s$. Prospective grantbacks, in contrast, by attenuating the licensee's rights to its own future innovations, can undermine incentives to innovate, and thus harm competition.

The Department of Justice investigated a grantback-type of condition in Microsoft's contracts with OEMs. The contracts required that Microsoft's licensees agree not to bring action against Microsoft or other licensees of Microsoft's software products for infringement of patents owned by the licensee, when those patents are necessary for the use and operation of Microsoft's software. The case raised antitrust concerns because the contract provisions applied to a large fraction of the personal computer OEM market and because of Microsoft's strong position in selling operating systems for PCs. A plausible efficiencies defense, however, is that the contract provision acted as an agreement to promote cross-licensing of potentially blocking innovations and thus increased the number of PCs running Windows and avoided potentially costly or market-disrupting litigation.

\section{Cross-Licensing and Patent Pools}

Owners of intellectual property often enter into reciprocal licensing agreements. Cross-licenses involving intellectual property for technologies that are complements or are in a blocking relationship serve a pro-competitive purpose. They can help solve the complementary monopolists problem identified long ago by Cournot, and they can avoid costly infringement disputes. Royalty-free cross-licenses promote the dissemination of technology. In addition, parties that wish to exchange intellectual property rights can use royalty-free cross-licenses as a means to shortcut the complexities of valuing each item of intellectual property.

Patent pools are agreements among firms to cross-license a category of intellectual property. Patent pools may take the form of royalty-free licenses for all technology owned by all of the pool members. Alternatively, the pool may impose a royalty structure, which may apply to pool members, to licenses with parties who are not members of the 
pool, or to both. The pool may cover only existing technology or may apply prospectively to include technology not yet discovered. The latter may include cross-licensing agreements that are incidental to a research joint venture.

The analysis of patent pools hinges in large part on the nature of the patents put into the pool. The central question is whether the patents going into the pool are substitutes or complements. If they are complements, any antitrust problems are typically more than offset by the efficiencies of assembling complementary intellectual property to enhance its usage. Pools involving competing patents are far more suspect, especially if the pool has the ability to set the royalty rate charged to third parties for the patents in the pool.

A pool of substitute patents, in addition to reducing competition in the licensing of those existing patents, can stifle future innovation if the pool is "prospective" in the sense that the members agree to contribute future patents to the pool. ${ }^{60}$ After all, the gains that one member of the pool captures from its innovative efforts are greatly muted if that member has previously agreed to share any new patents equally with all other members of the pool. This is especially so if the pool contains many members. ${ }^{61}$

Agreements to cross-license future technologies are more likely to raise antitrust concerns when the agreement extends to a large fraction of potential innovators. A case in point is United States $v$. Automobile Mfgrs. Association, in which the major U.S. automobile manufacturers agreed to exchange cross-licenses as part of a research joint venture to develop new motor vehicle pollution control equipment. ${ }^{62}$ The Department of Justice alleged that the effect of the joint venture was to retard rather than promote research and development. In particular, the department said, by agreeing to cross-license future technology to each other, the joint venture undermined the incentive of each manufacturer

60. Such a commitment can have attractive efficiency properties when complementary patents are involved, by assuring each participant that the others will not hold them up in their licensing of future complementary patents.

61. Of course, if the members also agree to consolidate their research operations and thus share R\&D costs as well as benefits, the analysis is quite different. This is the case of a research joint venture, which is beyond the scope of this paper. See Grossman and Shapiro (1986) and Katz (1986) for analyses of research joint ventures.

62. United States v. Automobile Mfgrs Association, 307 F.Supp 617 (C.D. Cal 1969). 
to gain an advantage in the development of new pollution control equipment and instead created a structure in which each manufacturer had an incentive to free-ride on the efforts of other members of the venture.

Patent pools and cross-licensing arrangements raise antitrust concerns when the parties to the agreement are actual or potential competitors either as owners of existing substitute IP or as innovators of future IP. An example of a cross-licensing arrangement for existing IP is the American Society of Composers, Artists, and Publishers, known as ASCAP, an association that establishes royalties for the performance of musical works. ASCAP licenses to bars, pubs, and taverns, to radio stations, to television stations, and even to the Girl Scouts. Members of ASCAP include composers and publishers who compete in the creation of musical scores. Yet the Supreme Court, in ASCAP-BMI, held that the association was not an illegal cartel because it allowed composers to license their works with substantial savings of transactions costs. ${ }^{6.3}$ ASCAP remains something of an anomaly in antitrust law, and the Antitrust Division of the Department of Justice has recently announced its intent to revisit the ASCAP case. ${ }^{64} \mathrm{~A}$ key question is whether the terms and conditions of ASCAP licenses have stifled competition among ASCAP's members.

Antitrust concerns arise regarding the membership rules for patent pools as well as the terms and conditions on which the members deal with each other and outsiders. In this respect, patent pools are similar to other consortiums, such as ATM networks, credit card networks, health care provider networks, and research joint ventures. Antitrust policy has been torn on these issues. One view is that competition is best served by a number of small networks or pools, which can then compete with one another. In this view consortiums should be kept small and should be free to limit their membership. ${ }^{65}$ Another view is

63. Broadcast Music, Inc., v. Columbia Broadcasting System, Inc., American Society of Composers, Authors, and Publishers v. Columbia Broadcasting System, Inc. 441 U.S. 1 (1979).

64. See "Cross-Licensing and Antitrust Law," an address by Joel I. Klein, acting assistant attorney general, to the American Intellectual Property Law Assn., San Antonio, Texas, May 2, 1997.

65. For example, when Dean Witter, which sought to issue Visa cards and Discover cards, sued Visa, Visa successfully argued that intersystem competition (Visa vs. Discover vs. American Express) would be harmed if Visa were required to offer a Visa membership to the entity controlling the Discover card. See Mountain West Financial Inc. v. Visa USA, Inc., 36 F.3d 958 (10th Cir., 1994). 
that firms excluded from a leading industry group are at a competitive disadvantage, making membership in a consortium a kind of essential facility. In this view consortiums should have open membership and may include a large fraction of industry members. We see no reason why the same structure of networks or patent pools is desirable across industries and for industry groups serving different functions; in any event, we will not resolve this debate here. We only point out that larger patent pools are potentially more troubling if it is feared that the pool serves to eliminate competition among its members.

\section{Settlements of Infringement Litigation}

Settlements of intellectual property disputes are fertile ground for cross-licensing because settlement is an inexpensive way to resolve costly litigation over interference claims. Patent pools are another settlement device. When complementary blocking technology is involved, these settlements are pro-competitive. Settlements are potentially hazardous to competition, however, if they involve competing technologies. Despite this fact the courts have generally been deferential to patent settlements. The IP guidelines state that the agencies will consider the competitive effect of settlements among competitors that involve cross-licensing.

An example of a settlement giving rise to a patent pool is United States v. Singer Manufacturing Co., in which the Supreme Court found that the dominant purpose of a patent settlement was not to settle the scope of each firm's patents, but rather to exclude a mutual competitor of the settling parties. ${ }^{66}$ The antitrust concern is that two patent holders will call a truce, knowing that their patents are weak or unenforceable, as a device for continuing to assert these patents against third parties. Of course, absent a smoking gun, it is difficult for the courts to assess the strength of the patents as perceived by the parties and thus to ascertain whether the settlement was a legitimate means of ending a costly legal dispute or a conspiracy to extract licensing royalties from others. A more recent example of a challenged settlement and patent pool involves the technology for laser eye surgery, in which two patent holders settled their infringement actions by putting their patents into a

66. United States v. Singer Manufacturing Co., 374 U.S. 174 (1963). 
common pool, which then charged licensing fees to each of them as well as to third parties. ${ }^{67}$

Settlements giving rise to territorial or field-of-use restrictions can likewise have anticompetitive effects. For example, a patentee facing stiff competition may sue a competitor with the chief aim of extracting a settlement in which the rival will agree to refrain from competing in certain fields of use or in certain territories. It is not sufficient to say that the extent of the restriction that the defendant in such a patent action would agree to reflects the likely validity and scope of the patent, because the two firms have an incentive to restrict competition via their settlement, at the expense of consumers, and this incentive can be powerful if there are few or no others in the market. In other words, antitrust agencies must be on the alert for competitors using settlement discussions as a cover for cartel activity.

Sometimes, settlements take the form of acquisitions. In these cases, merger analysis must ask whether the two firms would have been independent rivals in the absence of the merger. If one firm was clearly infringing on valid patents held by the other, a merger is a sensible solution to the problem. If, however, the patents being asserted are of questionable validity, or if the defendant in the patent action is likely not infringing, an acquisition as a means of settling the IP dispute can be anticompetitive. Precisely these issues arose when Boston Scientific acquired Cardiovascular Imaging Systems, in part to resolve patent disputes between the two companies in the area of catheter imaging technology. Asserting that this acquisition would have reduced competition in the market for the intravascular ultrasound catheters used in the diagnosis and treatment of heart disease, the FTC required that Boston Scientific license to Hewlett Packard or another commissionapproved licensee. ${ }^{68}$

\section{Standard-Setting and Patents}

A fascinating range of antitrust issues arise when patents are used in the context of standard-setting. We address a few salient issues here.

67. See Pillar Point Partners, Summit Partner Inc., and VISX Partner, Inc. v. David Dulanev, U.S. District Court, District of Arizona, CIV96-2051.

68. See the FTC Consent Decree with Boston Scientific Corp., Final Approval granted May 3, 1995, FTC Docket No. C-3573. 
TRUCE IN A STANDARDS WAR. Consider the common circumstance in which two or more firms or groups of firms are vying to establish the standard for the next generation of a consumer electronics device. One generic strategy is to fight it out in the market, a "standards war." Another approach is to negotiate a peace in the form of an industry standard. Even when an industry standard serves to enhance compatibility and overcome consumers' fears of being stranded with an obsolete technology, it can also soften competition between different formats. A key issue is whether consumers are harmed by a loss of variety or benefit from the enhanced compatibility. ${ }^{69}$

An example is the pooling of technology related to digital video disks to promote the next generation of compact disks. Pooling of complementary assets and capabilities should be encouraged in developing market standards; however, it may be difficult to distinguish this pro-competitive activity from other activity that may retard progress to a new standard, promote a less efficient standard, or reduce variety.

As a general rule, one should expect that sufficient competition will exist to develop a new product or market standard whenever more than a few independent entities exist that can compete to develop the product or standard. This rule of thumb is consistent with case law and conclusions in guidelines published by the U.S. antitrust authorities. For example, the IP guidelines conclude that mergers or other arrangements among actual or potential competitors are unlikely to have an adverse effect on competition in research and development if more than four independent entities have the capability and incentive to engage in similar R\&D activity. We have no easy answer in the more interesting case where the majority or the bulk of industry participants agree upon a standard, effectively short-circuiting any format war. We note, however, that consumers commonly welcome such standards, especially if the technology is truly "open" to all with little or no burden of licensing fees. Evidently, consumers typically would rather pay a few percentage points worth of royalties rather than lose significant compatibility benefits and avoid the danger of being left with orphaned equipment.

MANIPULATION OF THE STANDARDS PROCESS. Recent antitrust initiatives have focused on maintaining transparency in public standard-

69. See Farrell and Saloner (1986) for a discussion of the trade-off between standardization and variety. 
setting organizations and on avoiding the manipulation of these processes by dominant firms. In 1988 the Supreme Court found that a defendant had violated the Sherman Act by, among other actions, packing public meetings of the National Fire Protection Association (a private standard-setting organization) to force adoption of a biased safety code to benefit its product and disfavor competing products. ${ }^{70}$ In 1982 the Court held an association itself liable for the anticompetitive acts of its agents acting within the scope of their apparent authority where the agents used the association's safety standards against the plaintiff at the behest of one of its competitors. ${ }^{71}$

More recently, the FTC lodged a complaint against Dell Computer, alleging that Dell had failed to inform a standard-setting association that it owned a patent, along with Dell's assertion that it was aware of no such "essential" patent, until after the association adopted a standard that required the use of Dell's patented technology. The FTC alleged that Dell's failure to provide this information harmed competition by creating uncertainty in the industry about the value of the standard and by chilling the willingness of firms to participate in industry standard-setting efforts. ${ }^{72}$ In both the 1988 and the Dell cases, the antitrust laws were applied to police the internal governance of standard-setting bodies to promote more efficient industry outcomes.

Another interesting set of issues arises when participants in standardsetting bodies agree to license their essential patents on "fair, reasonable, and nondiscriminatory" (FRND) terms, such as are required by the International Telecommunications Union, the Telecommunications Industry Association, and the American National Standards Institute as a quid pro quo for official support of any standard. In several recent cases, including one involving Motorola and Rockwell regarding the technology embodied in the International Telecommunication Union's V.34 standard for $28.8 \mathrm{k}$ modems, disputes have arisen as to the meaning of FRND terms. ${ }^{73}$ One sensible interpretation of the FRND duty taken on by patent holders when seeking support in establishing a stan-

70. Allied Tube and Conduit Corp. v. Indian Head, Inc., 486 U.S. 492 (1988).

71. Amerian Society of Mechanical Engineers v. Hydrolevel Corp., 456 U.S. 556 (1982).

72. See the FTC Consent Decree with Dell Computer, Final Approval granted June 17, 1996, FTC Docket C-3658.

73. Motorola, Inc., v. Rockwell International Corp., Civil action 95-575-SLR (Del. 1995). 
dard is that the patentee be required to license on terms that reflect the patentee's ex ante superiority over alternative technologies, not the ex post lock-in that later arises once the standard is picked and investments have been made specific to that standard. This interpretation puts teeth into the FRND duty, at the cost of requiring an assessment of the ex ante market conditions, which is likely to be highly fact intensive.

INTERGENERATIONAL LEVERAGE. Leverage issues arise when a firm or firms controlling one generation of technology use that control to gain dominance over the next generation of technology or at least to gain an ongoing royalty stream from the next generation of technology.

Traditional antitrust principles of patent extension, as discussed earlier, tend to imply a harsh view of such "intertemporal leverage." Consider, however, the situation in which the sole supplier of a patented device refuses to license its patent to those seeking to make substitute next-generation products that are compatible with the patentee's device. ${ }^{74}$ Alternatively, the patentee could require that next-generation products conform to another technology in which it has intellectual property rights as a condition of licensing patents necessary for backward compatibility. The fact is, if the installed base is large and if compatibility is important, the patentee can have a significant competitive advantage in selling next-generation products, so long as the initial patent remains in force. It is certainly possible that the patentee could parlay its initial patent rights into ongoing dominance, extending well beyond the patent lifetime. For precisely this reason, it is important for industry participants to secure meaningful and lasting licensing commitments from those holding patents before the establishment of an industry standard.

\section{Conclusions}

The purpose of this article is to review developments in competition policy for the use and dissemination of intellectual property, with a focus on the Antitrust Guidelines for the Licensing of Intellectual Prop-

74. This strategy may not be available if the patent holder already has made commitments to license its patents on FRND terms. In that case, the breadth of the FRND duty may be critical: Does the duty apply only to first-generation devices, or does it extend to second-generation devices seeking backward compatibility? 
erty released in 1995 by the Department of Justice and the Federal Trade Commission.

We have provided a brief history of antitrust enforcement in the licensing of intellectual property, from the "Nine No-No's"' to the new guidelines, and we have reviewed recent IP enforcement actions by the Department of Justice and the FTC. Where appropriate, we have analyzed these actions using the theoretical apparatus we developed in the penalty section. An example is Microsoft's use of long-term contracts and "per-processor" royalties with its original equipment computer manufacturers. We also have linked our theoretical findings to the general approach described in the IP guidelines, noting, for example, the guidelines' emphasis on licensing arrangements that affect competition that would have occurred in the absence of the license.

A key issue that arises in many licensing contexts is the economic effect of licensing provisions that require some form of a commitment by the licensee to deal exclusively with the products of the licensor or to pay a penalty for using a rival technology. Such exclusivity provisions and penalty clauses can have clear efficiency benefits by promoting investments in technologies that would otherwise be subject to free riding and opportunism. These exclusivity arrangements also can deter entry, however, and lead to welfare losses.

The dangers of exclusive dealing provisions in licenses are most pronounced when the following conditions are present: (1) the licensor has a first-mover advantage, signing contracts before other potential innovators are themselves in a position to negotiate with licensees, as often occurs when one firm succeeds in innovating before its rivals; (2) there are multiple licensees who find it difficult to coordinate, so that each alone gives up little in agreeing to deal exclusively with the dominant firm, but collectively the cost is large; (3) there are scale economies and the incumbent licensor employs long-term, staggered licenses with exclusivity provisions; and (4) there are strong network effects in the market. Our formal analysis only relies upon the first condition holding.

We also pointed out some areas where the legal treatment of licensing practices lacks a firm economic foundation. The most striking examples are practices that both increase the rewards to innovators and reduce the deadweight loss associated with patent grants, yet are disfavored under the law. Whether one is concerned about long-run efficiency and 
rewards to innovation or short-run efficiency and traditional deadweight loss, such practices should not be enjoined. Yet the Supreme Court has decreed that licenses calling for royalties beyond the lifetime of the patent are flatly unenforceable. And tying involving intellectual property is treated quite harshly under antitrust law, even though such tying can simultaneously increase the rewards to innovation and reduce deadweight loss by enabling more effective metering of the use of the patented technology.

Our coverage of intellectual property issues is necessarily incomplete. For example, we have barely touched the important issue of refusals to license intellectual property and its treatment under the antitrust laws. Access to intellectual property and related compulsory licensing issues have acquired renewed policy interest with developments in the application of copyright laws to documents transmitted over data networks such as the Internet, and with the recent court of appeals decision requiring Kodak to sell patented parts to firms that compete in the service of its copier machines. ${ }^{75} \mathrm{We}$ also have not addressed a range of antitrust questions that are arising with increasing frequency in the area of technology standards, such as selective crosslicensing and pooling of patents among some members in the standardsetting process, or the manipulation of an interface by a dominant firm to disadvantage competitors. We can say with confidence, however, that these areas will continue to receive intense antitrust scrutiny as the information age unfolds and intellectual property plays an ever more important role in our economy.

\section{References}

Aghion, Phillippe, and Patrick Bolton. 1987. "Contracts as a Barrier to Entry."' American Economic Review 77 (June): 388-401.

Bernheim, B. Douglas, and Michael D. Whinston. 1996. Exclusive Dealing. NBER Working Paper 5666. Cambridge: National Bureau of Economic Research. July.

DOJ and FTC. 1995. "Antitrust Guidelines for the Licensing of Intellectual

75. Image Technical Services, et. al., v. Eastman Kodak Co., Opinion of the Ninth Circuit, August 26, 1997, Case No. CV-87-01686-AWT. The dangers of compulsory licensing are discussed in Gilbert and Shapiro (1996). 
Property.' ' Department of Justice and Federal Trade Commission, Washington, D.C. April.

Federal Trade Commission. 1996. "Competition Policy in the New High-Tech, Global Marketplace." Technical report. Washington, D.C. May.

Farrell, Joseph, and Garth Saloner. 1986. "Standardization and Variety." Economics Letters 20: 71-74.

Gilbert, Richard, and Carl Shapiro. 1990. "Optimal Patent Length and Breadth." RAND Journal of Economics 21 (Spring): 106-12.

. 1996. "An Economic Analysis of Unilateral Refusals to License Intellectual Property." Proceedings of the National Academy of Sciences, paper ed. 93 (23, Nov. 12): 12749-55.

Green, Jerry, and Suzanne Scotchmer. 1990. "Novelty and Disclosure in Patent Law." RAND Journal of Economics 21 (Spring): 131-46.

$\rightarrow$ Grossman, Gene M., and Carl Shapiro. 1986. "Research Joint Ventures: An Antitrust Analysis." Journal of Law, Economics, and Organization 2 (Fall): 315-37.

Kaplow, Louis. 1984. "The Patent-Antitrust Intersection: A Reappraisal." Harvard Law Review 97 (June): 1815-92.

Katz, Michael L. 1986. "An Analysis of Cooperative Research and Development." RAND Journal of Economics 17 (Winter): 527-43.

Mathewson, Frank G., and Ralph A. Winter. 1987. "The Competitive Effects of Vertical Agreements: Comment." American Economic Review 77 (December): 1057-62.

National Science Board. 1996. "Science and Engineering Indicators: 1996." Technical report 96-21. U.S. Government Printing Office.

Newberg, Joshua A., and Willard K. Tom. 1997. "U.S. Enforcement Approaches to the Antritrust/Intellectual Property Interface." In Competition Policy, Intellectual Property Rights, and International Economic Integration, edited by Nancy Gallini and Rob Anderson. Ottawa: Industry Canada.

Rasmusen, Eric B., J. Mark Ramseyer, and John S. Wiley, Jr. 1991. "Naked Exclusion." American Economic Review 81 (December): 1137-45.

Salop, Steven C. 1986. "Practices that (Credibly) Facilitate Oligopoly Coordination.' In New Developments in the Analysis of Market Structure, edited by Joseph E. Stiglitz and Frank G. Mathewson. MIT Press.

Scotchmer, Suzanne. 1991. "Standing on the Shoulders of Giants: Cumulative Research and the Patent Law." Journal of Economic Perspectives 5 (Winter): $29-41$.

Section of Antitrust Law, American Bar Assn. 1997. Antitrust Law Developments, 4th ed. St. Paul: West Publishing.

Segal, Ilya R., and Michael D. Whinston. 1996. "Naked Exclusion and Buyer Coordination."' Discussion paper 1780. Harvard Institute of Economic Research. 
1997. "Exclusive Dealing and Specific Investments." Technical report, Harvard University and the University of California, Berkeley.

Spier, Kathryn E., and Michael D. Whinston. 1995. "On the Efficiency of Privately Stipulated Damages for Breach of Contract: Entry Barriers, Reliance, and Renegotiation.' RAND Journal of Economics 26 (Summer): 180202.

U. S. Bureau of the Census. 1996. "Manufacturers' Shipments, Inventories, and Orders: 1982-1995." Technical report m3-1(95). U.S. Government Printing Office.

Weber, Robert James. 1988. "Probabilistic Values for Games." In The Shapley Value: Essays in Honor of Lloyd S. Shapley, edited by Alvin E. Roth. New York: Cambridge University Press.

Whinston, Michael D. 1990. "Tying, Foreclosure, and Exclusion." American Economic Review 80 (September): 837-59. 


\section{Comments}

Comment by Louis Kaplow: It is difficult to overstate the importance of intellectual property licensing or the complexity of the antitrust issues that it raises. Accordingly, Richard Gilbert and Carl Shapiro's paper is a welcome contribution. Indeed, the reader is treated to two papers for the price of one: first, an industrial organization paper that analyzes contractual penalty clauses; and, second, a tour through many of the antitrust policy problems involved with intellectual property licensing. What ties these papers together is that many antitrust concerns with licensing are illuminated by an understanding of penalty clauses. But that is not the case for other antitrust questions, and penalty clauses are significant independently of intellectual property licensing or, for that matter, antitrust.

\section{Contracts, Exclusivity, and Penalty Clauses}

The authors' analysis of contractual penalty clauses involves a scenario with a single seller and a single buyer-perhaps a licensor and a licensee of intellectual property-who enter into an initial contract before the arrival of an entrant. As is typical in this setting, the buyer and seller have an incentive to promote their own welfare at the expense of the entrant. This can be accomplished by provisions that penalize the buyer for subsequent dealing with the entrant.

In their model there is no ex post inefficiency, because if dealing with the entrant is efficient, it is assumed that the original contract will always be renegotiated to allow such dealing to take place in whatever manner is optimal. The extraction of rent from the entrant is, however, important for the efficiency of ex ante investments by each of the 
parties. For example (and perhaps of greatest relevance for antitrust policy), a prospective entrant may invest less in preparing for entry if it knows that some of the return on its investment-more than in the absence of the penalty clause - will be captured by the incumbent seller and the buyer.

My comments focus on the assumptions of this model.

ENTRANT NOT PRESENT. In the model it is assumed that the entrant is not present at the time of the initial contract between the buyer and seller. As the authors explain, this may often be true, particularly with regard to intellectual property licensing. A prospective entrant may not, at the outset of its research and development program, be in a position to negotiate a contract for a final product with a prospective buyer.

Interestingly, however, in each of the relevant applications discussed in the latter portion of the paper, the seller's important competitors, who may have been disadvantaged by penalty clauses, were present when those contracts were written. Thus, it would be useful to further develop the analysis for this case. With a single buyer, as in the authors' model, it would seem that extraction would no longer be possible, which raises the next issue.

SINGLE VS. MULTIPLE BUYERS. The model has a single buyer. The authors comment briefly on the problem with multiple buyers that has been analyzed in previous literature. In such cases, the seller is able to take advantage of the free rider problem among the buyers. Thus, a seller may be able to enter into contracts that are to the substantial disadvantage of buyers in addition to prospective competitors of the seller. The reason is that each buyer has little effect on the seller's market position in the subsequent time period, but when most buyers sign contracts with penalty clauses, their collective opportunities in the future will be reduced if, for example, entrants are thus deterred from entering.

In fact, the problem presented by the existence of multiple buyers is an important factor, perhaps the decisive factor, in the authors' subsequent applications. Relatedly, the problems posed by network externalities will be important in precisely this context. The authors agree that penalty clauses are most worrisome in the multiple-buyer context. I nevertheless emphasize this issue in these comments, lest the reader overlook it amid the extensive elaboration of the model, which emphasizes many unrelated subtleties. 
EFFICIENT EX POST RENEGOTIATION. The authors follow the trend of recent contracting literature by assuming that perfect renegotiation ensues upon the arrival of an entrant, thereby eliminating the possibility of ex post inefficiency. But, as a practical matter, renegotiation is unlikely to be costless. Indeed, when large numbers of buyers make coordinated renegotiation necessary, the costs and potential problems may be significant.

In addition, perfect renegotiation assumes that there is no asymmetric information between the parties. In some settings this assumption may be plausible, but in the case of intellectual property licensing, it is not. In essence the model assumes that all parties know (and agree upon) both the cost of using the technology and its value to ultimate consumers before the technology has come into use. Yet it seems more plausible that those who develop technologies, the seller and entrant in this model, know more about production using the technology and some aspects of potential demand, and the buyers, who may be engaged in aspects of production or in distribution and marketing, have proprietary information of their own. With trade secrets, where disclosure of what is being sold may tend to destroy its value, the problem of asymmetric information is particularly great. ${ }^{1}$ The possibility of ex post inefficiency should be taken seriously. On one hand, this complication makes the potential social costs of penalty clauses greater than suggested by the authors' model. On the other hand, such a prospect may tend to moderate contracting parties' attempts at rent extraction through penalty clauses because some of the ex post surplus that is destroyed might otherwise have been their own. ${ }^{2}$

REWARDS VS. PENALTIES. A final comment on the authors' model concerns a matter of interpretation. The analysis focuses on penalty clauses, under which the buyer pays the seller a penalty that is an increasing function of the extent to which the buyer purchases from the entrant. The extreme case of an exclusive dealing contract involves a prohibitive penalty for any positive purchases from the entrant.

1. Caves, Crookell, and Killing (1983) document the importance of imperfections in the market for technology licensing, and these imperfections probably explain particular features of existing licensing arrangements (such as the grant of an exclusive license with a royalty, which creates double marginalization, rather than a transfer of intellectual property rights for a fixed sum).

2. Aghion and Bolton (1987). 
It is useful to compare these sorts of penalties to rewards for purchasing from the seller, such as the offering of lower prices. Predatory pricing or royalty-free licensing are extreme examples of such rewards. The authors' analysis identifies some subtle differences between these two methods of inducing buyers to prefer dealing with the seller, but clearly rewards for purchasing from the seller and penalties for purchasing from others are similar. (In the limiting case in which final demand is totally inelastic, rewards and penalties tend to be the same; the difference in expected ex post transfers between the buyer and seller can be offset by adjustments to the value of the fixed transfer between the parties that is specified in the initial contract.) The main point is that rewards may involve externalities in a manner analogous to penalties, so antitrust analysis must be alert to the full range of mechanisms that may be used to disadvantage competitors.

\section{Antitrust Analysis of Intellectual Property Licensing}

Why is the antitrust analysis of intellectual property licensing so challenging? In addition to the frequent importance of vexing factual questions and intricate legal disputes (such as whether a party's patent is really valid), an important conceptual conflict is particularly hard to avoid in this context-namely, even if one could establish that a licensing scheme involved static inefficiency, the scheme may nevertheless be socially desirable if the ex ante incentive to innovate due to the additional reward is sufficiently great. Antitrust policy must deal with this difficulty.

Gilbert and Shapiro, drawing on the 1995 federal intellectual property guidelines, offer some useful general insights into this matter. They emphasize the flexibility of the antitrust laws and advance the principle that the scrutiny for intellectual property should be no more (or less) harsh than in other contexts. The real content of their approach comes in the broad range of licensing issues that they analyze, often by examining prominent cases.

In the course of their survey of problems and solutions, much of the emphasis is upon two factors: identifying ex post anticompetitive effects (as suggested by their test that asks whether more competition would have existed but for the license) and assessing whether there are likely to be any offsetting efficiencies. The efficiencies that they consider, 
however, are usually ex post as well; they do not always examine the ex ante inducement to innovation that is provided by various practices. In most contexts in which they offer a clear bottom line, my suspicion is that their answers are nevertheless appealing, but it is worth developing the analysis further to determine whether this is the case. ${ }^{3}$

CARTELS. Begin with the simplest of examples, which the authors illustrate with the Pilkington case, in which a firm is accused of using intellectual property licenses to organize a cartel in the industry. Economists generally believe that cartels are inefficient because of the deadweight loss that results from supracompetitive pricing. But does it follow that a cartel based on valid intellectual property, which does increase the reward to the innovator, is inefficient? After all, the central purpose of granting protection to intellectual property is to reward innovation by facilitating pricing in excess of marginal cost.

It turns out that permitting cartel organization does tend to be inefficient in this context. Suppose, for example, that a process innovation reduces production costs by $\$ 1$ a unit and that the innovator licenses the industry, nine other equal-sized producers, charging a royalty of $\$ 1$ a unit and also, through license restrictions (a price minimum, exclusive territories, or whatever), raising the price of the firms' final product by $\$ 10$. First, one should observe that in this scenario, 90 percent of the cartel profit goes to the other nine firms, not to the innovator; hence, society suffers the full deadweight loss, but only a small fraction of the resulting profit might serve as a reward to the innovator. Second, the profit attributable to cartelization, from the $\$ 10$ price increase, is vastly greater than the value of the innovation, so even if all of the profit went to the innovator the resulting inducement to innovation would be socially excessive. Thus, it is possible to distinguish the use of intellectual property to organize a cartel from the ordinary case of an innovator collecting a monopoly rent reflecting the value of its innovation.

PRICE DISCRIMINATION. A contrasting case, noted briefly by the au-

3. Most of the analysis that follows is drawn from Kaplow (1984), where I suggest that the relative desirability of various restrictive practices should be assessed by examining the ratio of the reward each practice generates to the deadweight loss it produces. This is, in essence, cost-effectiveness analysis, in which the question of the optimal level of reward is not addressed. With regard to the issue of reward, however, it is suggested that when a practice provides a reward in excess of the social value of the underlying intellectual property, the practice will be undesirable because such a reward will induce socially excessive ex ante investment. 
thors, is where license provisions-perhaps tying, differential royalties, or field-of-use restrictions-are used to facilitate price discrimination by the owner of intellectual property. In terms of static efficiency, price discrimination is relatively benign: deadweight loss may fall, be unaffected, or rise (but in an amount that is generally less than that associated with ordinary supracompetitive pricing). Suppose, for example, that in a particular case it is demonstrated that deadweight loss rises slightly but profits rise substantially as a result of some licensing practice. Here, a strong case could be made for allowing the practice, for it rewards innovation in an amount reflecting the true value of the innovation and in a manner that results in less static inefficiency per unit reward than is ordinarily the case. Moreover, in contrast to the cartel case, all of the incremental reward flows to the intellectual property owner.

COMBINATIONS OF COMPETING INTELLECTUAL PROPTERY. Consider a third case, in which holders of competing intellectual property rightsfor example, two patents that independently enable a new product to be produced-combine their claims. As the authors note, this may arise directly, through acquisition or merger, or in the somewhat more complex instance in which an intellectual property lawsuit is settled through some sort of pooling of rights.

It is suggested, in accordance with conventional wisdom, that such horizontal combinations should be prohibited. But the supporting analysis is wholly ex post: the concern is with the loss in competition between the two technologies, taking as given that the competing technologies were developed in the first place. If, in the absence of a combination, much of the reward to both innovators would be competed away, making combinations of intellectual property rights illegal would tend to reduce innovation.

Nevertheless, the view that horizontal combinations of intellectual property are detrimental seems likely to be correct. After all, the only social benefit from the second innovation arises if there would be competition, so there would be no loss-and, in fact, an efficiency gain from avoiding wasteful $R \& D$ expenditures - if the second innovation were not developed. The second version will be socially valuable only to the extent that it is better than the first, but to this extent the innovator would be able to charge a higher royalty in a competitive interaction. 
Obviously, this problem admits of several variations, and the analysis depends upon the nature of the competitive interaction among the innovators (are all rents dissipated, or only some?), whether innovation is simultaneous or sequential, the extent of uncertainty involved in $\mathrm{R} \& \mathrm{D}$, and other factors. Accordingly, further research is appropriate before reaching confident conclusions concerning the likely net social consequences of permitting the combination of competing technologies.

STANDARD-SETTING. The authors' analysis of standard-setting in industries subject to network externalities is worth exploring further. Initially, consider why it might be undesirable for a standard to be protected by an intellectual property monopoly, such as when a firm has intellectual property that must be used by other firms seeking to meet the industry standard. First, such a monopoly may produce substantial deadweight loss ex post even if the value of the innovation was slight. (In the extreme case, the choice of the standard among a range of alternatives, each cheaply developed, may be arbitrary.) Second, the prospect of such a monopoly may induce costly rent-seeking behavior in order to have one's own proprietary method become the industry standard. One might also be concerned that the wrong (less efficient) technique will become the standard, as in the case in which a formal standards-setting process is subverted or, perhaps, when a firm uses contracts with penalty clauses to line up customers in sufficient quantity to tip the market in favor of its technology.

This set of problems involves both antitrust law and intellectual property law. With respect to the latter, one might ask whether intellectual property protection should apply, say, to an arbitrary technique that can be developed cheaply in instances in which it becomes an industry standard. Of course, the problem with simply denying intellectual property protection is that some techniques become standards precisely because they are better, and the prospect of reward provides incentives for developing superior methods. Accordingly, the authors favor a regime under which a firm's licensing of technology that is required to meet a standard must be done on "fair, reasonable, and nondiscriminatory"' (FRND) terms. In particular, they emphasize that the appropriate royalty should reflect the ex ante superiority of the technique over competing methods, not the additional hold-up value that arises once the industry is organized around a particular standard. 
The problem, of course, is that it will be difficult to determine what royalty level would be appropriate, and ex post litigation of such an issue would be expensive and of dubious accuracy.

As a solution, at least in settings in which some organization or government body sets the standard, it might be possible to obtain advance agreement from the firm whose technology is to be chosen. In particular, a firm could be asked not merely to agree to license on FRND terms, but to agree on those particular terms in advance, for example, licensing all comers for a royalty of $x$ per unit. Before the standard is chosen, firms proffering competing techniques will have an incentive to bid against each other on royalties (and other terms), and those determining the standard can consider both the value of the technology and the attractiveness of its price. This possible solution also suggests that there may be advantages in having standards explicitly chosen by a formal process rather than allowing them to emerge in the marketplace. Yet there are obvious competing dangers: the body making the choice might be subverted in some manner or, even if it behaves benevolently, it may lack the information that is implicitly brought to bear in a decentralized market.

Comment by Robert Gertner: Rich Gilbert and Carl Shapiro have written an excellent paper that links modern economic theory to the antitrust issues of intellectual property licensing. The paper should be important reading for many who are not up on the theoretical literature but who care about what the modern theory has to say about the practices and vice versa. The authors provide a useful framework for analyzing the welfare effects of intellectual property licensing practices and demonstrate how to apply the framework to a series of antitrust cases. It is a paper that will be not only widely cited, but also widely read.

I find the model useful for thinking about the externalities associated with restrictions in contracts between buyers and sellers. The model does what it purports to do-provides a framework for thinking about a wide variety of practices and shows how much of the existing literature fits in. The authors care about using the model, so they worry about the robustness of the results. Nonetheless, I think further consideration of the effects of costly renegotiation would be fruitful. Related to this, the model puts no restrictions on renegotiation that includes both the 
entrant and the seller. These parties are horizontal competitors and some forms of bargaining could violate antitrust laws.

Much of the value of the model comes from its useful framework for thinking about ideas we have seen before-it is not news that we should think about the foreclosure effects of Microsoft's per-processor license, but the model helps make the analysis clear and should help ground the policy and legal debate in appropriate economics.

The most important theoretical insight deals with the importance of whether the entrant is present at the time of the negotiation between the buyer and the seller. The authors show that if the entrant is not present, the scope for anticompetitive behavior is greatly enhanced. This strikes me as being of significant practical importance and probably often overlooked. Other useful insights include clarifications of the role of renegotiation and differences in contract restrictions on the ability to use contracts to suppress competition.

The model applies to more than intellectual property licensing, and the authors realize that. It applies to any firm that contracts downstream and owns a scarce asset that gives it some market power. Exclusive contracts for scarce physical inputs are little different from exclusive contracts for intellectual property. There is no intellectual property licensing in Benetton's arrangement with its retailers. Benetton sells some inputs and the use of its brand name and takes a fraction of the revenue. This is not very different form Microsoft's per-processor license fee.

This raises the question whether there is any reason to treat vertical practices associated with intellectual property differently from other property. The paper does not, and all of the analysis seems to apply equally to other forms of property. I think two important distinctions could have implications for antitrust enforcement. First, explicit government policy specifies the extent of intellectual property protection. Governments determine the length and scope of copyright and patent protection. This opens the door to consideration of the trade-off between the scope of intellectual property protection and antitrust enforcement. The same expected payoff from innovative activity can be achieved by increasing patent length and adopting more restrictive antitrust rules. This trade-off presents policymakers with an additional tool that is not typically an option for other forms of property. The second important distinction is that intellectual property creates significant contracting 
problems not present with other forms of property. Because intellectual property can be copied at a very low cost, a licensee has the ability to both use and resell it. Contracts must protect against this type of piracy, and therefore forms of licensing intellectual property should be different from and more complex than licensing other types of property.

The second half of the paper is very informative about a wide range of practices and antitrust cases involving these practices. I find myself agreeing with virtually every detail, which makes it impossible for me to do what is common for a commentator of a good paper-quibble about the details. Instead, I am forced to reverse course and talk about some of the hard issues that the authors do not really take on. I like doing this as a commentator because I am allowed to raise issues without being expected to have anything insightful to say about resolving them.

The authors state in their abstract [not printed in this volume] that they "indicate those areas in which the law and the economics are in harmony, and those areas where the law is untethered from economics." They do not summarize the level of harmony, but my reading suggests that they feel it is quite high. They are rule-of-reason fans: given that all these practices may not be anticompetitive in some cases, they do not like per se rules here. The modus operandi for the paper is to discuss how a particular type of restriction fits into their model and then look at a number of examples from antitrust cases or investigations. They show how the contract may be anticompetitive and describe the legal outcome. They rarely, however, get to the level of asking the extent to which the standard applied in the case is in harmony with the economic model. Rather, they look for something much weakerwhether or not courts or enforcement authorities address the appropriate economic issues in applying a rule of reason. My reading of the paper is that the authors think that things in general are okay, even though courts appear confused at times, for example, by seeing coercion in some contracts and trying to make decisions based on that perception.

I now want to address the question of the appropriate standard for antitrust enforcement for intellectual property licensing in these settings This is a very difficult question, both in theory and in practice. Everyone admits the difficulty of the latter, but few debate the appropriate standard in a world of costless enforcement and perfect evidence. I want to do this first. 
Much of what I say derives from my experiences teaching strategic management to MBA students. I will think about the problems from the licensor's perspective-the seller in the model. This is a firm that owns a strategic asset-it could be intellectual property, a real asset, a valued brand name, market share in the presence of switching costs, or a unique organizational architecture. A path to economic profits, the driving force of competition and capitalism, is through developing and exploiting these strategic assets. Sometimes this exploitation involves the exercise of monopoly power, but, I think, more often than not companies are simply trying to maximize the scarcity rents associated with the asset.

Let me give an example from my competitive strategy course-one concerning the Walt Disney Company and feature animation. The company's strategic assets include a strong reputation for quality products in the minds of consumers, high-quality animators and writers, leading technology, scale efficiencies, marketing advantages from video sales of old films, and many others. These assets allow Disney to make economic profits and convey some market power. Disney has a legitimate business goal of exploiting these assets through strategies such as promotional tie-ins, aggressive distribution, long-term contracts with animators, and integration into theme parks, television networks, and retail stores. Part of the effect of these strategies is to make entry less attractive and to reduce an entrant's investment. Discouraging competitors from entering is part of the return from the adoption of these strategies, and for all I know (I don't), it may be part of the internal calculation of the returns from these strategies. Yet the main reason for taking these actions is not anticompetitive, nor is it really efficiencyenhancing in the short run. The main reason is to increase rents from is unique position in the market that results from its investments and decisions over fifty years.

Do we want a regulatory framework that requires Disney management and its lawyers to make welfare calculations to determine if any of these decisions violates antitrust laws? A pure rule-of-reason analysis, which Gilbert and Shapiro appear to favor, implies the answer is yes. I think the answer is no. A pure rule-of-reason standard creates an environment where any firm that has legitimate market power must act as a social welfare maximizer with respect to many of its decisions. The burden or discretion such a regime gives to the legal and regulatory 
communities and the effect on the long-run incentives for firms are potentially very dangerous.

This raises the question of defining the limits of the scope of antitrust inquiries and setting the standard for liability. Antitrust practice tends to categorize business practices as anticompetitive or efficiency-enhancing, but long-run efficiency derives from the process of seeking scarcity rents, which sometimes can be separated from the acquisition of some market power.

There are many possible standards. The authors quote one suggested by Charles Rule that would allow practices that exploit the area under the demand curve but not practices that shift the demand curve. This standard would make illegal virtually all practices designed to exploit a strategic asset. Louis Kaplow's proposed standard, which would weigh gains from the practice against welfare losses, can serve as a guiding principle, but it begs the question of the base for the comparison of gains and losses. One possible base is no license at all. This is a very weak standard and would certainly not result in an enforcement action against Microsoft for its licensing practices because the welfare decline from no licensing of DOS by Microsoft would be enormous. Because Gilbert and Shapiro appear to be sympathetic to an enforcement action against Microsoft, they must have another standard in mind. It would be nice to know what that standard is. Another possibility is to ask how the licensor can best achieve its legitimate goals without the anticompetitive effects and use this as a comparison. This approach quickly becomes a form of a less-restrictive alternative test. How clever do we insist firms must be in devising contracts that achieve legitimate goals without anticompetitive effects? How do we define "legitimate goals"? Do we incorporate the effects of a practice on the incentives to innovate, and do we consider the costs of entry in making the assessment? I think these questions are difficult, deep, and fundamental. They are difficult without even considering the important effects of prosecutorial and agency discretion, the incentives for private lawsuits, and treble damages.

These problems of defining the appropriate standard do not incorporate the very important uncertainty and costs inherent in determining the effects of many of these practices. The complications are enormous. An analogy to predation is useful. Our current theoretical understanding of predation is that situations may exist where welfare declines and a 
firm can benefit from lowering prices, inducing exit, and subsequently raising prices. Some believe that such situations are rare and costly to find and the costs of mistakes are large, so the practice should be legal. Others believe it is not so rare and needs to be deterred, so a rule-ofreason approach should exist.

Nonetheless, courts and economists of all persuasions reject a fullblown rule-of-reason approach in predation. Remember, price below marginal cost (or average variable cost, or any other cost measure) is not necessary for welfare-reducing predation. The challenge has been to design a rule that can be understood and implemented effectively that does a reasonable job of separating the good from the bad.

The large debate that has resulted from this predation question has not yet been repeated with respect to intellectual property licensing, but the problem is quite analogous. Once it is accepted that these practices may be anticompetitive under an appropriate theoretical standard, yet in many situations represent a fundamental way for firms to compete, the goal is to come up with effective rules that limit the inquiry and provide reasonable safe harbors. Gilbert and Shapiro's paper offers so much insight into and knowledge of the economics and practice of intellectual property licensing that I wish they had taken on these very hard fundamental problems. Because I have made little progress in resolving them, I would like to hear what they have to say.

\section{Commentators' References}

Aghion, Philippe, and Patrick Bolton. 1987. "Contracts as a Barrier to Entry.", American Economic Review 77 (June): 388-401.

Caves, Richard E., Harold Crookell, and J. Peter Killing. 1983. "The Imperfect Market for Technology Licenses." Oxford Bulletin of Economics and Statistics 45 (August): 249-67.

Kaplow, Louis. 1984. "The Patent-Antitrust Intersection: A Reappraisal." Harvard Law Review 97 (June): 1813-92. 